UNIVERSIDADE DE SÃO PAULO

ESCOLA DE ENFERMAGEM

INTERAÇÕES MEDICAMENTOSAS POTENCIAIS: UM ESTUDO DOS ANTIMICROBIANOS UTILIZADOS EM PACIENTES SUBMETIDOS A TRANSPLANTE DE MEDULA ÓSSEA

ROSIMEIRE BARBOSA FONSECA GUASTALDI

SÃO PAULO

2006 
ROSIMEIRE BARBOSA FONSECA GUASTALDI

\title{
INTERAÇÕES MEDICAMENTOSAS POTENCIAIS: UM ESTUDO DOS ANTIMICROBIANOS UTILIZADOS EM PACIENTES SUBMETIDOS AO TRANSPLANTE DE MEDULA ÓSSEA
}

\begin{abstract}
Dissertação apresentada ao Programa de Pós Graduação em Enfermagem na

Saúde do Adulto da Escola de

Enfermagem da Universidade de São

Paulo para obtenção do título de Mestre.
\end{abstract}

Orientador:

Profa. Dra. Silvia Regina Secoli

SÃO PAULO

2006 


\section{Dedicatória}

Dedico este trabalho à minha família:

Aos meus pais, Josafá e Vandeci pelo amor e por tudo que me ensinaram...

Ao Leandro, meu marido, pelo amor, companheirismo e compreensão...

A todos da minha família, por serem grandes incentivadores do meu trabalho. 


\section{Agradecimentos}

A Deus, por ter me guiado sempre.

À Prof ${ }^{a} \operatorname{Dr}^{a}$ Silvia Regina Secoli pelo jeito especial de ensinar, que com sua sabedoria, experiência e paciência soube conduzir-me na realização deste estudo e orientar-me para muito além desta Tese.

À $\mathscr{D}^{a}$ Eutália A.C. de Araújo pela experiência e dedicação nas análises estatísticas.

À Profa Dr $^{a}$ Cibele Andruciolli de Mattos Pimenta pelo apoio e por ter feito o encaminhamento inicial ao mestrado

À $\mathscr{D}^{a}$ Eliane Ribeiro, pelas sugestões realizadas no exame de qualificação

À Profa $\mathscr{D}^{a}$ Maria Angélica Perterlini, pelas sugestões realizadas no exame de qualificação

Ao $\operatorname{Prof}^{\circ} \mathscr{D}^{\circ}$ Paolo Meneghin, pelo carinho e contribuições relativas à discussão desta pesquisa

Ao $\operatorname{Prof}{ }^{\circ} \mathscr{D}^{\circ}$ Dirceu Carrrara pelo apoio e sugestões para a realização deste trabalho Ao Serviço de Educação Continuada do Instituto do Coração HCFM-USP e equipe de enfermagem do campo de estudo, pela colaboração na fase de coleta de dados.

À Marisa Perez pela dedicação na formatação desta dissertação A Sra $\mathcal{N a d i r , ~ p e l o ~ c u i d a d o ~ n a ~ r e v i s a ̃ o ~ d a s ~ r e f e r e ̂ n c i a s ~ b i b l i o g r a ́ f i c a s ~}$

Às funcionárias da secretaria do Departamento de Enfermagem Médico Cirúrgica da Escola de Enfermagem da Universidade de São Paulo pelo carinho e paciência

A todos que de alguma forma incentivaram e contribuíram para o desenvolvimento deste trabalho 


\section{RESUMO}

Guastaldi RBF. Interações medicamentosas potenciais: um estudo dos antimicrobianos utilizados em pacientes submetidos ao transplante de medula óssea [Dissertação]. São Paulo (SP): Escola de Enfermagem da USP; 2006.

O presente estudo caracterizou o perfil farmacológico utilizado por pacientes submetidos a transplante de medula óssea (TMO), identificou as combinações existentes entre antimicrobianos potencialmente interativos e outros medicamentos decorrentes da co-administração e analisou, a partir das combinações identificadas, as interações medicamentosas (IM) potenciais quanto aos seguintes aspectos: tipo de IM, nível de severidade, evidência cientifica e implicações clínicas potenciais. Analisaram-se 70 prescrições de medicamentos de pacientes submetidos a TMO, que se encontraram na fase de condicionamento (dia -1), e que estiveram internados, no período de janeiro a junho de 2005 , no Instituto do Coração do Hospital das Clinicas da Faculdade de Medicina da Universidade de São Paulo. Os dados relativos ao perfil terapêutico dos medicamentos foram coletados do prontuário do paciente, e aqueles acerca das IM foram obtidos por meio de consulta ao Drug Interactions Facts e Drug Interactions Handbook. Para análise dos dados utilizou-se estatística descritiva e analiinferencial sendo aplicada a regressão logística multivariada. Os resultados apontaram que a amostra foi composta em sua maioria por pacientes do sexo masculino (52,9\%), com média de idade de 37 anos, com diagnósticos de linfomas $(38,6 \%)$ e submetidos a transplantes do tipo autólogo (65,7\%). Quanto ao perfil terapêutico observou-se 33 medicamentos distintos pertencentes a 8 classes terapêuticas com predomínio dos quimioterápicos (34\%). Observou-se que $72,7 \%$ dos medicamentos apresentaram potencial para interação medicamentosa, sendo que $79,2 \%$ eram precipitadores. Quanto à análise das características farmacológicas que predispunham as IM verificou-se que $66,6 \%$ dos medicamentos afetavam o metabolismo hepático, inibindo-o $(45,8 \%)$ ou estimulando-o (20,8\%). Entre os quimioterápicos antimicrobianos $66,7 \%$ apresentaram características potencialmente interativas. Metade da amostra foi exposta a combinações de antimicrobianos potencialmente interativos (fluconazol, ciprofloxacina e sulfametoxazol+trimetoprima) e outros medicamentos; sendo identificadas $13 \mathrm{IM}$ distintas, todas do tipo farmacocinética. A maioria das IM (92,3\%) apresentou severidade moderada, com bom nível de evidência cientifica $(61,6 \%)$, que poderiam resultar em elevação dos níveis séricos do agente combinado com o antimicrobiano $(77,0 \%)$, com tempo de inicio dos efeitos demorado (61,5\%). Houve associação estatisticamente significante entre ocorrência de IM e sexo $(p<0,001)$; entre $I M$ e faixa etária $(p<0,001)$; entre $I M$ e número de medicamentos $(p<0,001)$. 


\begin{abstract}
Guastaldi RBF. Potential drug interactions: An anti-microbial study using patients who undergo bone marrow transplant. [Thesis - Masters degree] São Paulo(SP) - Brazil: Nursing School, University of São Paulo - USP; 2006.
\end{abstract}

The present study have characterized the pharmacologic profile used by patients who undergo bone marrow transplant (BMT); identified the existing combinations between the potentially interactive anti-microbial drugs and those deriving from co-administration; and analyzed, using identified combinations, the possible drug interactions (DI) in regard to the following aspects: type of DI, severity level, scientific evidence, and potential medical implications. There were analyzed 70 prescriptions medication for patients who underwent a BMT in the phase of conditioning (day -1), and who were in the hospital within the period of January to June 2005, in the Heart Institute of the School of Medicine Hospital of the University of São Paulo (Instituto do Coração do Hospital das Clinicas da Faculdade de Medicina da Universidade de São Paulo). The data related to the medication therapy profile were collected from the patient handbook and the DI data were obtained by looking up in the Drug Interactions Facts and Drug Interactions Handbook. For data analysis, the description and inferential statistics were used and the multi-diverse logistic regression was applied. The results pointed out that the sample was primarily of patients of masculine gender $(52,9 \%)$, with an average age of 37 years old, with lymphoma diagnosis $(38,6 \%)$ and who were undergoing auto-transplants $(65,7 \%)$. In regard to therapeutic profile, there were observed 33 different drugs from 8 therapy classes mainly of chemotherapy (34\%). $72,7 \%$ of the medications showed to be potentially drug interactive, whereas $79,2 \%$ of them were precipitators. As for the pharmacology characteristic analysis that predisposes DI, it was verified that $66,6 \%$ of the medications affected the hepatic metabolism by inhibiting it $(45,8 \%)$ or stimulating it $(20,8 \%)$. Among the anti-microbial chemotherapy drugs, $66,7 \%$ presented potentially interactive characteristics. Half of the sample were exposed to anti-microbial combinations potentially interactive (fluconazole, ciprofloxacin e sulphamethoxazole+trimethoprim) and other medicaments; where 13 different DI were identified, all of them of the pharmacokinetic type. Most of the DI (92,3\%) presented moderate severity, with good level of scientific evidence $(61,6 \%)$, which could result in a higher level of serum of the agent when combined with the anti-microbial drugs $(77,0 \%)$, with prolonged time for starting the effects $(61,5 \%)$. There was a statistically significant association between the DI occurrence and sex $(p<0,001)$; between DI and 40-49 year-old age-group ( $p<0,001)$; between DI and more than 4 number of medicaments $(p<0,001)$. 

. 


\section{LISTA DE TABELAS}

Tabela 1 - Distribuição da amostra segundo sexo, diagnósticos e tipo de transplante de medula óssea. São Paulo, 2005.

Tabela 2 - Distribuição dos pacientes segundo variáveis quantitativas. São Paulo, 2005 . . 41

Tabela 3 - Analise descritiva dos medicamentos utilizados pelos pacientes submetidos a transplante de medula óssea, segundo respectivos horários de aprazamento. São Paulo, 2005.

Tabela 4 - Distribuição dos medicamentos utilizados em transplante de medula óssea segundo classificação terapêutica Alfa, nome genérico e número de pacientes submetidos à terapia. São Paulo, 2005.

Tabela 5 - Distribuição dos medicamentos utilizados por pacientes submetidos a transplante de medula óssea segundo potencial interativo. São Paulo, 2005... 47

Tabela 6 - Distribuição dos medicamentos utilizados por pacientes submetidos a transplante de medula óssea segundo classificação . São Paulo, 2005.

Tabela 7 - Distribuição dos medicamentos utilizados por pacientes submetidos a transplante de medula óssea, segundo características farmacológicas que predispõem a interação medicamentosa . São Paulo, 2005.

Tabela 8 - Distribuição dos quimioterápicos antimicrobianos utilizados por pacientes submetidos a transplante de medula óssea segundo potencial interativo. São Paulo, 2005.

Tabela 9 - Distribuição dos quimioterápicos antimicrobianos utilizados por pacientes submetidos a transplante de medula óssea, segundo características farmacológicas que predispõem a interação medicamentosa. São Paulo, 2005.

Tabela 10 - Distribuição dos pacientes submetidos a transplante de medula óssea, segundo exposição às combinações existentes entre antimicrobianos potencialmente interativos e outros medicamentos. São Paulo, 2005.

Tabela 11 - Distribuição dos pacientes submetidos a transplante de medula óssea, segundo exposição às interações medicamentosas potenciais do fluconazol. São Paulo, 2005.

Tabela 12 - Distribuição dos pacientes submetidos a transplante de medula óssea, segundo interações medicamentosas potenciais com a ciprofloxacina. São Paulo, 2005.

Tabela 13 - Distribuição dos pacientes submetidos a transplante de medula óssea, segundo interações medicamentosas potenciais com o sulfametoxazol +trimetoprima . São Paulo, 2005.

Tabela 14 - Nível de severidade das interações medicamentosas potenciais dos antimicrobianos São Paulo, 2005.

Tabela 15 - Nível de evidência cientifica das interações medicamentosas potenciais dos antimicrobianos. São Paulo, 2005.

Tabela 16 - Nível de risco de terapia combinada das interações medicamentosas potenciais dos antimicrobianos. São Paulo, 2005.

Tabela 17 - Associação entre interações medicamentosas potenciais e variáveis demográfico-clínicas. São Paulo, 2005. 


\section{LISTA DE FIGURAS}

Figura 1 - Números anuais de transplantes de medula e sangue no mundo (1970-2000) . 12

Figura 2 - Tipos de infecções pós-transplante de medula óssea 14

Figura 3 - Exemplos de inibidores e substratos do sistema enzimático citocromo $P_{450}$.......22

Figura 4 - Exemplos de indutores e substratos do sistema enzimático citocromo $P_{450} \ldots . . .22$

Figura 5 - Níveis de significância clínica das interações medicamentosas .........................26

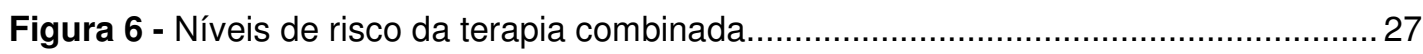

Figura 7 - Transplantes de medula óssea realizados no INCOR-HCFMUSP. São Paulo, 2000-2005.

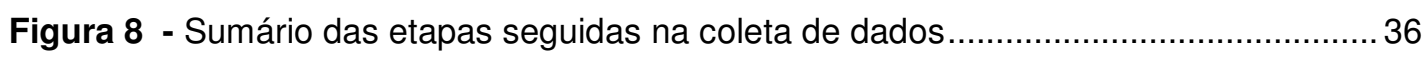

Figura 9 - Interações medicamentosas segundo o nível de severidade .............................37

Figura 10 - Interações medicamentosas segundo o nível de evidência científica.................38

Figura 11 - Interações medicamentosas segundo o nível de risco da terapia combinada.. 38

Figura 12 - Distribuição dos pacientes segundo medicamentos administrados em 24h.

São Paulo, 2005

Figura 13 - Distribuição dos pacientes segundo horários de medicamentos aprazados. São Paulo, 2005

Figura 14 - Média de medicamentos aprazados nos horários. São Paulo, 2005 44

Figura 15 - Medicamentos utilizados por pacientes submetidos a transplante de medula óssea segundo classificação terapêutica Alfa São Paulo, 2005.

Figura 16-Tipos de interações medicamentosas potenciais e respectivos processos alterados. São Paulo, 2005

Figura 17 - Interações medicamentosas potenciais e respectivas implicações clínicas, evidências cientificas e tempo de inicio dos efeitos. São Paulo, 2005 54

Figura 18 - Interações medicamentosas potenciais e respectivos níveis de severidade e risco para terapia combinada. São Paulo, 2005 


\section{SUMÁRIO}

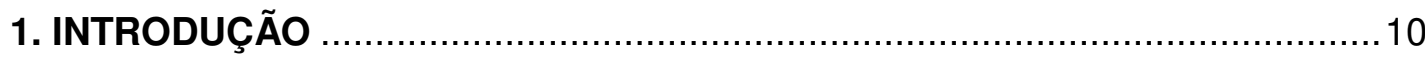

1.1. Transplante de medula óssea: procedimento, tipos e terapia

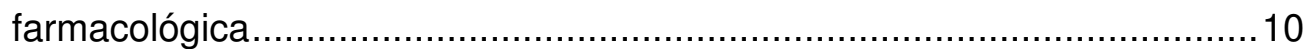

1.2. Interações medicamentosas: epidemiologia, mecanismo e classificação...15

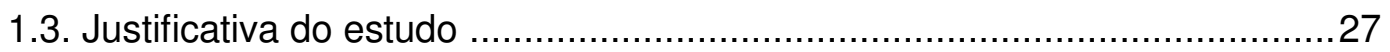

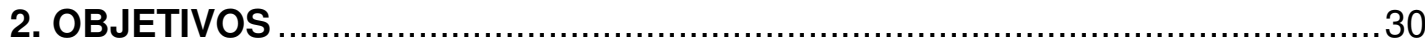

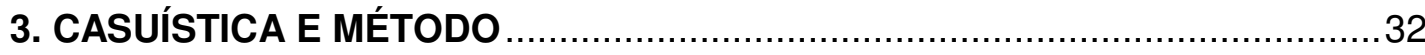

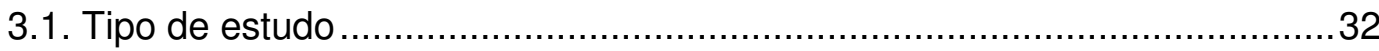

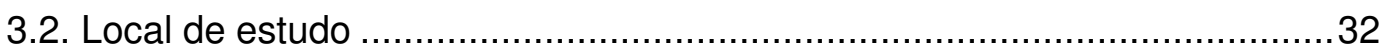

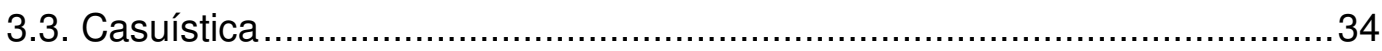

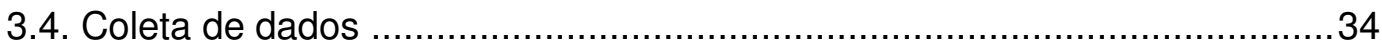

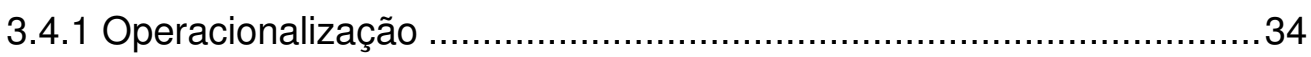

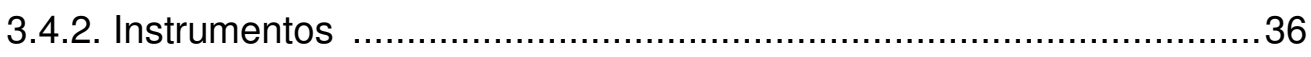

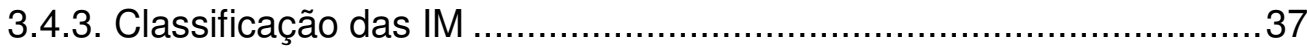

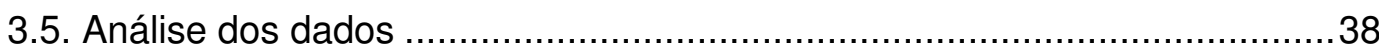

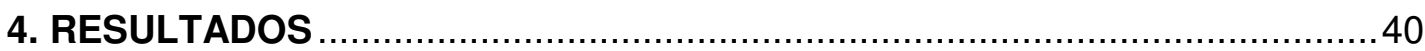

4.1. Caracterização dos pacientes quanto às variáveis demográfico- clínicas e ao perfil de aprazamento dos horários da prescrição médica. ...................40 40

4.2. Perfil da terapia farmacológica.............................................................4 44

4.3. Perfil das combinações entre antimicrobianos potencialmente interativos e outros medicamentos

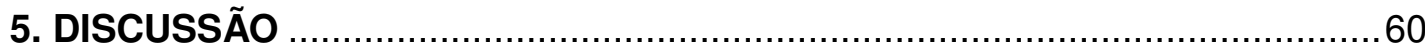

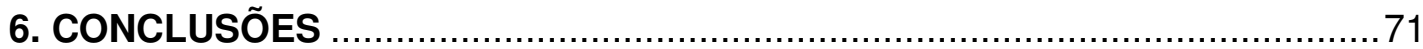

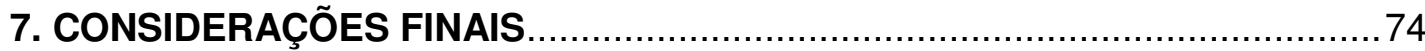

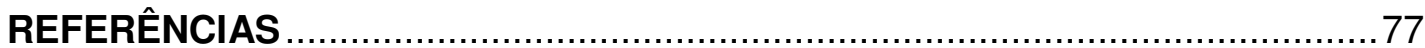

ANEXO 
Introdução 


\section{INTRODUÇÃO}

\subsection{Transplante de medula óssea: procedimento, tipos e terapia farmacológica}

O Transplante de medula óssea (TMO) representa uma das principais modalidades terapêuticas, para os pacientes com diagnósticos de doenças oncológicas, hematológicas e congênitas, que oferece a possibilidade de ampliar o período de vida. Neste tipo de terapia é, inicialmente, realizada aplasia medular do receptor e posteriormente infusão venosa de células do tecido hematopoiético, previamente tratadas ou de doador compatível, com a finalidade de restabelecimento da hematopoiese $^{(1,2)}$.

$\mathrm{Na}$ atualidade, o procedimento de TMO tem crescido de modo expressivo, especialmente em países desenvolvidos. Estima-se que 30 a 50 mil transplantes sejam realizados anualmente por todo o mundo, e este número aumenta de 10 a $15 \%$ por ano ${ }^{(2,3)}$. O registro europeu de TMO apontou que de 2000 a 2001 foram realizados cerca de 5000 transplantes autólogos, aumentando para 7000, a partir de 2002. O registro internacional de TMO possui mais de 492 centros de transplantes em todo o mundo, e este número eleva-se anualmente ${ }^{(3)}$.

O primeiro relato de um TMO alogênico com sucesso ocorreu em março de 1969, em Seattle - Estados Unidos da América - EUA, quando um paciente com leucemia recebeu medula óssea de seu irmão, após ser submetido a altas doses de irradiação corporal total. Este procedimento foi realizado pelo Dr. E. Donnal Thomas e seu grupo, o qual possui até hoje a vanguarda da pesquisa em $\mathrm{TMO}^{(4)}$.

No Brasil, o primeiro TMO ocorreu em 1979, no Hospital das Clinicas da Universidade Federal do Paraná. Em 1988 foi inaugurada uma unidade de TMO no Hospital das Clinicas da Faculdade de Medicina da Universidade de São Paulo (HCFMUSP). Desde então o número de 
transplantes em todo o Brasil vem aumentando de modo significativo. Em 1995 foram realizados 247, em 1998 foram 503 e em 2000 aumentou para 623. Destes, 314 foram realizados no Estado de São Paulo, ou seja, 50\% dos $\mathrm{TMO}^{(5)}$.

Os TMOs são classificados em três grandes classes: singênico, alogênico e autológo (auto-transplante), os quais são identificados pela relação existente entre receptor e doador ${ }^{(4,6)}$. O TMO tipo singênico ocorre quando a medula óssea é retirada de um irmão gêmeo idêntico. No TMO alogênico, o paciente recebe a medula de um doador vivo, preferencialmente parente, ou doador desconhecido encontrado nos bancos de medula óssea. Há subtipos do TMO alogênico, sendo cada um nomeado de acordo com a compatibilidade do HLA (antígeno de histocompatibilidade), podendo ser total ou parcial em alguns casos. O tipo relacionado ou aparentado ocorre quando o doador é um parente, preferencialmente irmão, e o não-relacionado ou não aparentado é quando o doador não tem relação de parentesco com o receptor. No autológo, as células progenitoras são coletadas do próprio paciente, tratadas e criopreservadas para posterior utilização(4,6,7) .

Os TMO realizados no período de $1980-2000$, de acordo com o tipo são ilustrados na Figura 1. 
Figura 1 - Números anuais de transplantes de medula e sangue no mundo (1970-2000)

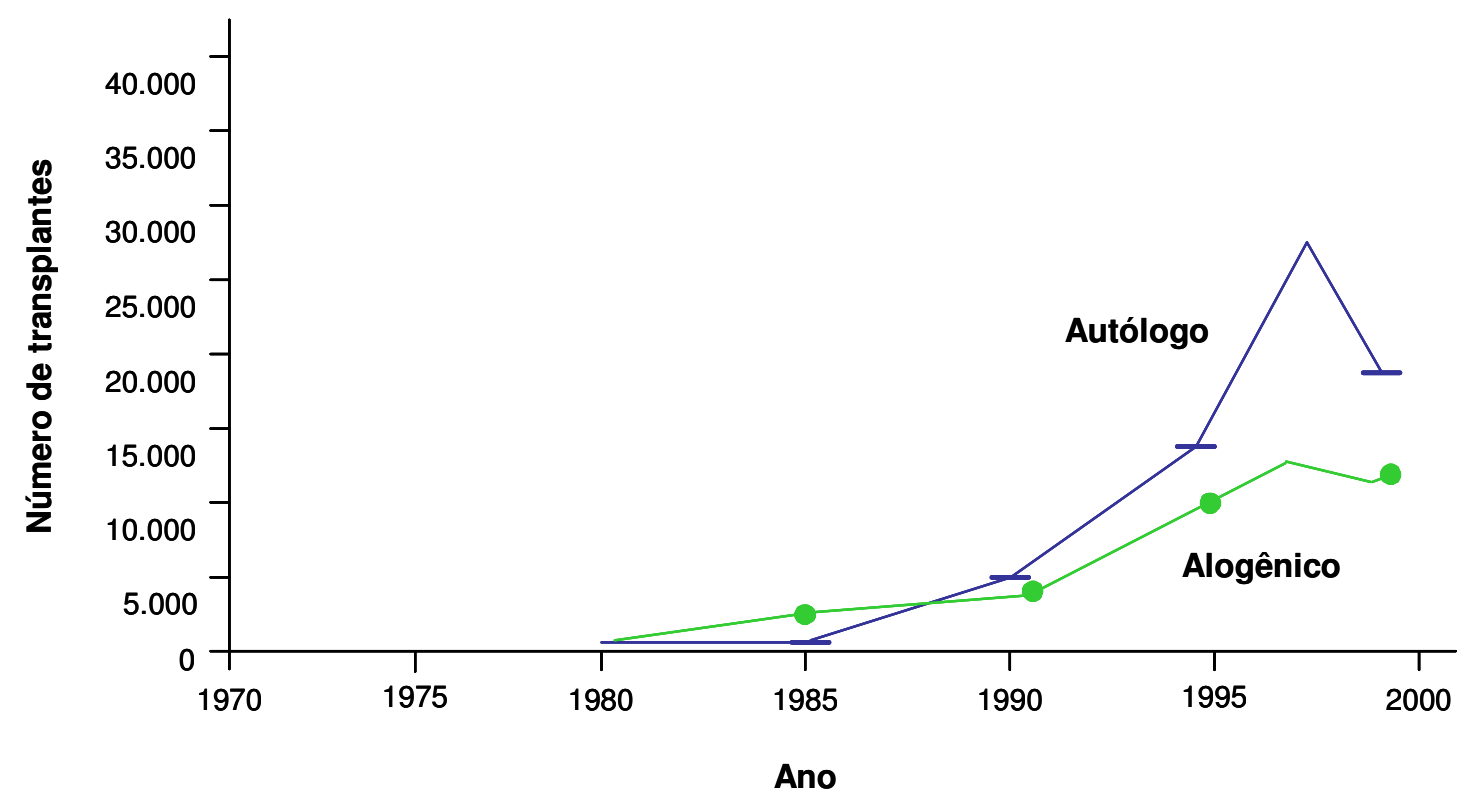

Fonte: Barros, JC; 2006.

O procedimento do TMO é didaticamente dividido nas fases: prétransplante e transplante (condicionamento e infusão) ${ }^{(1)}$.

A fase pré-transplante tem a finalidade de avaliar o paciente, definir o tipo de transplante e doador, e orientar receptor e doador quanto aos procedimentos. Deste modo, os pacientes realizam os exames diagnósticos e testes laboratoriais de compatibilidade com os doadores. Além disso, são feitos esclarecimentos aos pacientes e familiares quanto à terapia. Após o aceite da família e do paciente, implanta-se um cateter venoso central de longa permanência, cujo objetivo é a coleta de exames, hemoterapia e quimioterapia, e os pacientes são encaminhados para internação.

A fase do transplante é subdividida em duas etapas: condicionamento e infusão da medula óssea. O condicionamento consiste na administração de altas doses de quimioterápicos antineoplásicos e/ou irradiação corpórea total, que tem como finalidade a destruição de células neoplásicas, induzindo aplasia medular. Inicia-se então, uma contagem 
regressiva no primeiro dia de quimioterapia, sendo o dia da infusão da medula denominado de "zero". Os regimes ablativos de condicionamento são variados, e os principais agentes utilizados são ciclofosfamida, bussulfano, melfalano, carmustina, vepeside e arabinosídeo C. Em muitos casos emprega-se a irradiação corporal total ${ }^{(1,4,8)}$. Os quimioterápicos de escolha apresentam toxicidades relevantes e poucas informações clínicas sobre as interações entre os medicamentos ${ }^{(8)}$.

É durante a fase do condicionamento que se inicia, também, a terapia adjuvante com antieméticos, anti-histamínicos, corticosteróides, analgésicos, imunossupressores, protetores gástricos e, particularmente antimicrobianos com o propósito de evitar, reduzir ou aliviar reações adversas (RAMs) decorrentes da quimioterapia antineoplásica ou ainda, prevenir complicações ${ }^{(9-12)}$.

A infusão da medula óssea é realizada na unidade de internação, apresentando uma duração, geralmente, de 40 a 60 minutos, sendo feita através de um cateter venoso central. Nesta fase inicia-se a hidratação intravenosa do paciente e administração de medicamentos como corticosteróides, anti-histamínicos e ansiolíticos, que visam à prevenção de intercorrências transfusionais.

$\mathrm{Na}$ fase pós-transplante os pacientes permanecem em aplasia medular (pancitopenia) e os leucócitos, plaquetas e hemácias começam a aumentar no período de 15 a 25 dias após infusão da medula óssea. Nos primeiros 100 dias pós-TMO costumam ocorrer muitas complicações, porém, estas, também podem ocorrer tardiamente. Dentre as principais complicações do período pós-transplante destacam-se anemias, mucosites graves, sangramentos, dores e infecções, que são decorrentes do condicionamento ou da infusão de medula óssea ${ }^{(13)}$.

A complicação infecciosa é uma das mais graves, podendo ser causada por fatores como mucosites, neutropenia, pancitopenia e disfunção da imunidade celular ${ }^{(13)}$. Deste modo, durante o período de neutropenia são 
comuns infecções por citomegalovírus, bacteremias, fungemias, aspergiloses e infecções do trato urinário e aquelas relacionadas ao cateter venoso central ${ }^{(14-16)}$. Os agentes infecciosos, bem como a gravidade das infecções varia de acordo com o diagnóstico e idade do paciente, tipo de transplante, imunoprofilaxia utilizada pelo paciente e sexo do doador ${ }^{(11,14,17)}$.

Ao longo das fases do TMO, os medicamentos são introduzidos na terapia a fim de aliviar sintomas, prevenir e tratar complicações decorrentes do procedimento. A farmacoterapia utilizada é complexa e inclui, principalmente, antimicrobianos que são utilizados para evitar e reduzir a morbi-mortalidade decorrente de infecções - complicação grave e freqüente nos pacientes submetidos ao $\mathrm{TMO}^{(7)}$.

Deste modo, no âmbito do TMO, constitui prática freqüente, a utilização de regimes terapêuticos combinados com antimicrobianos de classes terapêuticas distintas. A terapia profilática com estes agentes varia de acordo com a flora de microorganismos patogênicos de cada serviço e o tempo de TMO do paciente, conforme ilustra a Figura $2^{(7)}$.

Figura 2 - Tipos de infecções pós-transplante de medula óssea

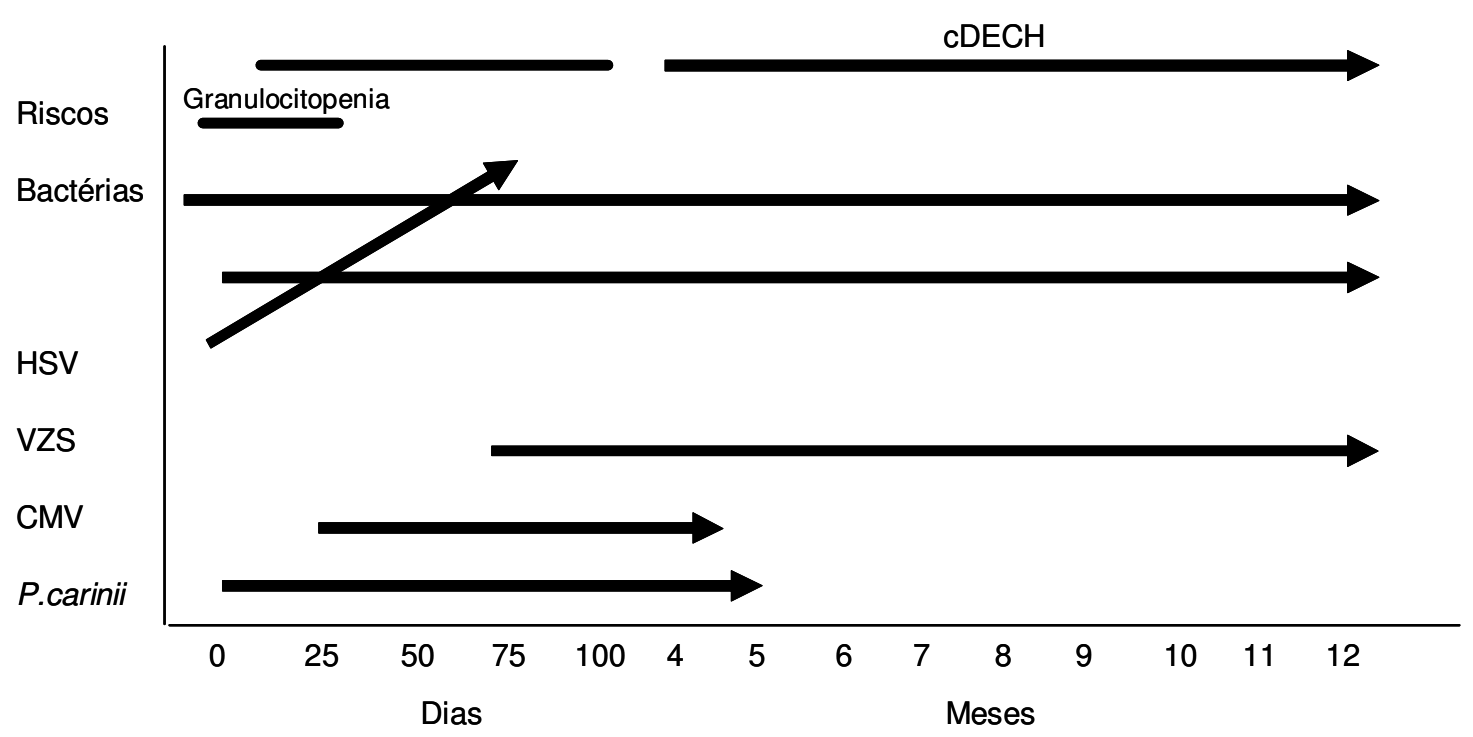


Neste cenário em que a terapia farmacológica, principalmente antimicrobiana representa um dos principais pontos para o sucesso do procedimento, e que as associações são utilizadas como importante estratégia terapêutica, é fundamental discutir a questão das interações entre os medicamentos como um dos principais fatores que interferem no resultado terapêutico do paciente submetido ao TMO.

\subsection{Interações medicamentosas: epidemiologia, mecanismo e classificação}

$\mathrm{Na}$ atualidade as interações medicamentosas (IM) têm se constituído em importante objeto de investigação. $O$ número de medicamentos disponibilizados no mercado é grande, a polifarmácia é uma estratégia utilizada no tratamento de várias doenças, as conseqüências das IM, muitas vezes, encontram-se relacionadas a reações adversas, que são reconhecidas como um importante problema de saúde, tendo em vista que podem levar ao insucesso terapêutico sem mostrar nenhum dano aparente no paciente ${ }^{(18)}$

Autores clássicos definem IM em termos da ação de um medicamento sobre 0 outro, sendo denominado precipitante 0 medicamento que interfere no mecanismo de ação de outro, e objeto o agente cuja ação farmacológica ou concentração foi alterada ${ }^{(19-23)}$. O termo IM, também, é utilizado para descrever a interação entre medicamentos e alimento, álcool, tabaco, solvente ou poluente $e^{(19,20,23)}$.

As respostas decorrentes das IM podem ser desejadas ou indesejadas. São desejadas e necessárias na medida em que reduzem os efeitos colaterais ou melhoram a eficácia terapêutica dos agentes combinados. São indesejadas quando prejudiciais à terapia, podendo aumentar as RAMs e causar ineficácia terapêutica ${ }^{(23-25)}$. 
A incidência das IM é variada. Segundo os informes em Farmacovigilância da Agência Nacional de Vigilância Sanitária (ANVISA), a incidência de IM oscila entre 3-5\%, para pacientes que fazem uso de diversos medicamentos e pode aumentar para $20 \%$ ou ainda mais, em usuários que recebem de 10 a 20 agentes $^{(26)}$.

As pesquisas têm mostrado que $37-60 \%$ dos pacientes admitidos em hospitais podem apresentar uma ou mais combinações de medicamentos como fator de risco para $\mathrm{IM}^{(27-32)}$. Para pacientes hospitalizados o risco para o evento aumenta, certamente pelo numero de agentes incluídos na prescrição. Estudo realizado com pacientes clínicos concluiu que a média de medicamentos prescritos na alta foi maior (6) do que na admissão $(4.5)^{(27)}$.

Na Europa, uma pesquisa feita com 1601 idosos mostrou que em média eles utilizavam 7 medicamentos por dia, e que $46 \%$ das prescrições apresentou IM potenciais ${ }^{(33)}$.

Um trabalho realizado em hospital universitário com prescrições médicas de pacientes admitidos numa unidade de clínica médica, mostrou que $100 \%(n=40)$ da amostra que utilizou 10 ou mais medicamentos foi exposta a uma ou mais IM potenciais, e que 65\% das prescrições continham pelo menos uma IM potencial ${ }^{(34)}$.

Em cardiologia, uma investigação realizada com pacientes ambulatoriais apontou uma média de 8,7 receitas médicas por paciente, e a ocorrência de 145 IM potenciais que poderiam causar arritmia ventricular fatal ${ }^{(35)}$. Outro estudo mostrou que pacientes com hipertensão recebiam em média dois anti-hipertensivos, e que $74 \%$ da amostra apresentou pelo menos uma IM potencial, sendo que para $35 \%$ destes a interação foi considerada grave $\mathrm{e}^{(36) \text {. }}$

Estudo realizado num hospital público analisou $\mathrm{IM}$ de antidepressivos, apontando que nas unidades de internação geral (25\%) e 
nas de psiquiatria (20\%) a freqüência de IM foi maior que no hospital dia $(16 \%)^{(37)}$.

Em pacientes onco-hematológicos identificou-se que na fase pósquimioterapia $72,7 \%$ dos pacientes usaram 14 a 22 medicamentos em $24 \mathrm{~h}$, e que $95,5 \%$ deles foram expostos à associação de medicamentos potencialmente interativos como 0 alopurinol + sulfametoxazol+trimetoprina ${ }^{(38)}$.

Em pacientes com tumores sólidos e hematológicos verificou-se que a amostra recebeu de 1 a 20 medicamentos durante a internação, com uma média de 8 agentes por $\operatorname{dia}^{(39)}$.

Num estudo com pacientes críticos $(n=70)$, cuja média de medicamentos utilizados foi 14,7 detectaram-se 102 IM potenciais em 44,3\% dos pacientes (1,5 IM por paciente) ${ }^{(40)}$.

Uma investigação realizada com idosos admitidos num setor de emergência mostrou que $74,5 \%$ receberam mais que um medicamento diariamente, e 65\% apresentou IM potenciais. Os autores verificaram, ainda, que o número de IM potenciais aumentou de acordo com a quantidade de medicamentos usados, de modo que aqueles que receberam um número superior a $8(83 \%)$ foram expostos a inúmeras $\mathrm{IM}^{(41)}$.

No contexto da saúde pública, uma pesquisa em unidades básicas de saúde identificou prescrições com média de 2 medicamentos para indivíduos com idade inferior a 59 anos e 4 medicamentos para aqueles com mais de 59 anos. Dentre as prescrições com 5-7 medicamentos 50\% apresentou $\mathrm{IM}^{(42)}$.

No setor de emergência 52,6\% das prescrições médicas apresentou IM decorrentes do aprazamento simultâneo de medicamentos realizado pela equipe de enfermagem ${ }^{(43)}$. 
Segundo alguns estudos, os medicamentos mais implicados nas IM graves são aqueles utilizados em clínica médica como anti-hipertensivos, antianginosos, antiagregantes plaquetários, diuréticos, corticosteróides, depressores do sistema nervoso central, anticonvulsivantes e antidepressivos inibidores seletivos de recaptação de noradrenalina e serotonina $^{(27,35,36,40,42,44)}$.

A variação na incidência das IM observada nos estudos destacados parece estar relacionada ao local da pesquisa (ambulatório, hospital), as classes terapêuticas envolvidas, as características da amostra investigada (idade, sexo, estado fisio-patológico, tipo de alimentação), ao modo de administração dos medicamentos (dose, via, intervalo e sequência da administração) e aos hábitos dos profissionais quanto às prescrições e uso irracional de medicamentos ${ }^{(22-24)}$. No entanto, a despeito de haver vários fatores relacionados, o número de medicamentos utilizados pelo paciente representa um elemento fundamental na ocorrência das IM.

A gravidade, freqüência e possíveis conseqüências das IM estão relacionadas a fatores como idade avançada, condições clínicas e principalmente características dos medicamentos ${ }^{(22-24,45)}$.

A idade avançada representa um fator importante, visto que pacientes que geriátricos, apresentam mudanças no organismo como distribuição da água, massa muscular e gordura corporal, que afetam o metabolismo e eliminação dos medicamentos, aumentando a meia-vida ( $\left(t^{1} / 2\right)$ e, conseqüentemente a atividade farmacológica destes agentes ${ }^{(24,45)}$. Assim, o processo de envelhecimento contribui para o aumento das IM do tipo farmacocinético ${ }^{(45,46)}$.

Há que se destacar, ainda, que pacientes idosos comumente fazem uso de polifarmácia porque possuem, muitas vezes, inúmeras doenças e sintomas desconfortáveis associados ao processo de envelhecimento ${ }^{(24,45,46)}$. Estudos desenvolvidos para a prevenção de IM mostraram que é bastante comum entre os idosos, o uso de 2-6 prescrições 
médicas associadas e a auto-medicação com mais de 2 medicamentos ${ }^{(47,48)}$. Tal fato tem preocupado os profissionais responsáveis pela farmacoterapia, tendo em vista que o uso simultâneo de mais de 6 agentes pode elevar o risco IM graves em até $100 \%^{(47,48)}$. Assim, a administração concomitante de medicamentos para este grupo de risco deve ser feita com cautela, realizando-se ajuste posológico e avaliando-se o risco e o benefício ${ }^{(46,45)}$.

Os pacientes que apresentam doenças crônicas como cardiopatias, hepatopatias, nefropatias e aquelas que acometem o sistema imunológico apresentam, freqüentemente comprometimento dos sistemas orgânicos responsáveis pela distribuição, metabolização e eliminação dos medicamentos, o que eleva a meia-vida (t $1 / 2$ ), o risco das RAMs e de $\mathrm{IM}^{(47,49)}$. Além disso, são tratados por período prolongado e submetidos a polifarmácia, que incluí a utilização de anti-hipertensivos, diuréticos, anticoagulantes, imunossupressores, corticosteródes e quimioterápicos antineoplásicos - agentes que freqüentemente encontram-se envolvidos em $\mathrm{IM}^{(24,45)}$.

A qualidade das prescrições médicas, em pacientes com doenças crônicas, encontra-se diretamente relacionada à necessidade de hospitalização. Pacientes com insuficiência cardíaca são, muitas vezes, admitidos nos serviços devido a prescrições inadequadas, contendo dosagem incorreta e medicamentos de diferentes e inúmeras especialidade $^{(49)}$.

A característica do medicamento representa uma variável importante que, inclusive, pode ajudar a predizer o potencial de interação de cada um, independente do seu uso nas terapias combinadas. Os medicamentos que apresentam potencial para interagir (potencialmente interativos) são denominados precipitadores e objetos, dependendo das suas características farmacocinéticas ${ }^{(22-24)}$.

São chamados precipitadores aqueles agentes que ${ }^{(22)}$ : 
a) possuem alta ligação às proteínas plasmáticas (PP), que deslocam os medicamentos objeto dos sítios de ligação às PP. $O$ deslocamento de um agente do seu sítio de ligação às PP por outro, eleva seu nível sérico.

b) modificam (induzem ou inibem) o metabolismo de outros. A indução do metabolismo de um agente objeto por um precipitador pode diminuir o nível sérico do primeiro, enquanto a inibição do metabolismo de um agente objeto por um precipitador pode aumentar o nível sérico do primeiro.

c) alteram a função renal e a depuração de medicamentos objeto.

Os medicamentos chamados objeto são aqueles que apresentam uma curva dose-resposta com inclinação abrupta, ou seja, cuja alteração da dose, por menor que seja, causa modificação expressiva no efeito farmacológico. São exemplos de medicamentos objeto os aminoglicosídeos, os anticoagulantes, os anticonvulsivantes, os anti-hipertensivos, os quimioterápicos antineoplásicos, os imunossupressores, os glicosídeos cardíacos, os anticoncepcionais orais e os medicamentos com ação no sistema nervosos central ${ }^{(22)}$.

Autores consagrados classificam as IMs em dois tipos farmacocinéticas e farmacodinâmicas - de acordo com a fase em que ocorrem $^{(19-23)}$.

As interações farmacocinéticas são caracterizadas por interferirem no padrão de absorção, distribuição, metabolização ou excreção dos medicamentos. Este tipo de IM é frequentemente verificado pela mudança em um ou mais parâmetros cinéticos do medicamento como o nível sérico, $t \frac{1}{2}$, total de medicamento excretado na urina, entre outros ${ }^{(19-23)}$.

A alteração no padrão de absorção decorrente de IM pode ocorrer com medicamentos administrados por via oral, tópica e parenteral, tendo como fatores importantes, as mudanças no $\mathrm{pH}$ do sistema digestório, a 
velocidade de esvaziamento gástrico, o tônus e a motilidade da musculatura intestinal e a presença de substâncias como, cálcio, alumínio, magnésio e sais de ferro e formulações farmacêuticas ${ }^{(19,22-24)}$. Alguns antiácidos alteram o pH gástrico e podem aumentar ou diminuir a absorção de outros medicamentos dependendo de sua composição. A metoclopramida aumenta o esvaziamento gástrico e propicia a absorção de outros medicamentos ${ }^{(23)}$.

As IM que afetam a distribuição dos medicamentos, ou seja, o transporte destes da corrente sangüínea para órgãos e tecidos, ocorrem quando agentes que possuem alta ligação às PP deslocam outros de seus sítios de ligação às PP, aumentando a fração livre elevando, assim, o nível sérico $^{(20,22)}$. Esta fração livre é responsável pela atividade farmacológica do medicamento. Por exemplo, o nível sérico da varfarina pode ser elevado através da co-administração com a aspirina, que apresenta alta ligação às PP. O resultado desta IM é o aumento do potencial hemorrágico do anticoagulante ${ }^{(23,24)}$.

A alteração no processo de metabolismo dos medicamentos decorrente de IMs ocorre através das enzimas hepáticas, as quais podem ser inibidas ou induzidas por alguns medicamentos, denominados inibidores e indutores enzimáticos, respectivamente ${ }^{(19,20,22-24)}$.

O sistema enzimático mais envolvido em IM é o citocromo $\mathrm{P}_{450}$ $\left(C Y P_{450}\right)$ encontrado no retículo endoplasmático de células, que são predominantes no fígado e intestino, e é responsável pelo metabolismo de aproximadamente $75 \%$ dos medicamentos ${ }^{(20)}$. Este sistema é formado por um grupo de enzimas que apresenta cerca de 40 tipos de isoenzimas. Estas são agrupadas em super famílias (CYP1, CYP2) e subdivididas em subfamílias (CYP2D6). A sigla CYP2D6 significa isoenzima 6 pertencente à subfamília $D$ da família $2^{(20,23) \text {. }}$

As IM relacionadas ao metabolismo acontecem quando um medicamento (objeto) é inibido ou induzido por outro (precipitador) A indução enzimática de um determinado agente (objeto) causada por outro 
(precipitador) resulta na diminuição dos níveis séricos do primeiro, o que causa conseqüentemente mudança no efeito farmacológico ${ }^{(22,23)}$.

Em relação ao sistema enzimático $\mathrm{CYP}_{450}$, os medicamentos podem ser considerados inibidores, indutores e substratos. Os inibidores e indutores enzimáticos são os medicamentos conhecidos como precipitadores, e os substratos são os medicamentos objeto, ou seja, aqueles que são metabolizados por uma ou mais enzimas $\mathrm{CYP}_{450}$. Exemplos de inibidores, indutores e respectivos substratos são ilustrados nas Figuras 3 e $4^{(20)}$

Figura 3 - Exemplos de inibidores e substratos do sistema enzimático citocromo $\mathrm{P}_{450}$

\begin{tabular}{|l|c|c|c|c|c|c|c|c|}
\hline \multirow{2}{*}{ Inibidor/ Substrato } & \multicolumn{7}{|c|}{ Enzimas do sistema citocromo P450 } \\
\cline { 2 - 8 } & 1A2 & 2-6 & 2B6 & 2C8/9 & 2C19 & 2D6 & 2E1 & 3A4 \\
\hline $\begin{array}{l}\text { Cimetidina } \\
\text { Pimozida }\end{array}$ & $\diamond$ & & & & & $\diamond$ & & $\diamond$ \\
& $\diamond$ & & & & & & & $\diamond$ \\
\hline $\begin{array}{l}\text { Ciprofloxacina } \\
\text { Teofilina }\end{array}$ & $\diamond$ & & & & & & & $\diamond$ \\
\hline $\begin{array}{l}\text { Fluconazol } \\
\text { Sertralina }\end{array}$ & & & & $\diamond$ & $\diamond$ & & & $\diamond$ \\
\end{tabular}

$\diamond$ - enzimas inibidas

Figura 4 - Exemplos de indutores e substratos do sistema enzimático citocromo $P_{450}$

\begin{tabular}{|l|c|c|c|c|c|c|c|c|}
\hline \multirow{2}{*}{ Indutor/Substrato } & \multicolumn{7}{|c|}{ Enzimas do sistema citocromo P450 } \\
\cline { 2 - 8 } & 1A2 & 206 & 2B6 & 2C8/9 & 2C19 & 2D6 & 2E1 & 3A4 \\
\hline $\begin{array}{l}\text { Carbamazepina } \\
\text { Propranolol }\end{array}$ & $\diamond$ & & & & & $\diamond$ & & $\diamond$ \\
& & & & & $\diamond$ & $\diamond$ & & \\
\hline $\begin{array}{l}\text { Fenitoína } \\
\text { Teofilina }\end{array}$ & $\diamond$ & & & & & & & $\diamond$ \\
\hline $\begin{array}{l}\text { Rifampicina } \\
\text { Diazepam }\end{array}$ & & & & $\diamond$ & $\diamond$ & & & $\diamond$ \\
\end{tabular}

$\diamond$ - enzimas induzidas

A inibição enzimática pode ocorrer através de diversas reações químicas, de modo que os inibidores impedem que as enzimas metabolizem outros medicamentos. Além das isoenzimas do CYP 450 , as colinesterases, a 
monoamino-oxidase (MAO) e a aldeído-desidrogenase são enzimas que podem ser inibidas ${ }^{(20,23)}$.

A inibição enzimática resulta em aumento do nível sérico do medicamento objeto, com conseqüente elevação do seu potencial tóxico. As enzimas responsáveis pela metabolização tendem a ficar saturadas quando são utilizadas por dois medicamentos ao mesmo tempo. A inibição parece mostrar um efeito rápido na resposta clínica ${ }^{(19)}$.

A indução enzimática nada mais é que a estimulação da atividade da enzima responsável pelo metabolismo, com conseqüente aumento desta substância. Este processo, ao contrario da inibição, é mais lento em decorrência da necessidade de síntese da enzima ${ }^{(19)}$.

As IM que modificam a excreção encontram-se relacionadas às alterações na capacidade de filtração glomerular, secreção e reabsorção no túbulo renal, que conseqüentemente, interferem no tempo de ação dos medicamentos $^{(23)}$. As IM que ocorrem no túbulo renal são, muitas vezes, utilizadas para prolongar o tempo de ação de alguns medicamentos através do mecanismo de competição. Um exemplo clássico é a co-administração de probenecida e penicilina, quando a primeira aumenta o tempo de ação do antibiótico, pois reduz a secreção deste pelo túbulo renal ${ }^{(23)}$. As IM desta fase podem, ainda, ser decorrentes de alterações no $\mathrm{pH}$ urinário, que interferem na ionização de ácidos fracos como, por exemplo, a intoxicação por fenobarbital (ácido fraco) requer a administração de bicarbonato de sódio para aumentar a eliminação do barbitúrico ${ }^{(23)}$.

As interações farmacodinâmicas são aquelas que provocam mudanças nas respostas dos pacientes sem alterar a farmacocinética do medicamento objeto e sem mudanças no nível sérico ${ }^{(19)}$. Este tipo de IM ocorre, geralmente, no local de ação dos medicamentos, afetando o mecanismo de ação, a relação entre concentração e efeito, o que resulta na variação das respostas farmacológicas. Podem ocorrer através de sinergismo ou antagonismo ${ }^{(19-24)}$. 
A IM que resulta em sinergismo ocorre quando há combinação de dois ou mais medicamentos, e o resultado clínico da combinação é maior que os efeitos isolados $(1+1>2)^{(19)}$. A associação de medicamentos com toxicidades nos mesmo órgão como aminoglicosídeos e vancomicina, pode resultar em um sinergismo de nefrotoxicidade ${ }^{(19,23,24)}$.

$\mathrm{O}$ antagonismo é um tipo de IM em que um medicamento possui efeito oposto ao outro administrado no mesmo regime $(1+1<2)^{(19)}$. Esta $\mathrm{IM}$, geralmente, acontece quando há competição pelos mesmos sítios de ligação da molécula-alvo. Um exemplo clássico de antagonismo é a administração do naloxone (antagonista de opióde) para reverter os quadros de depressão respiratória após uso de morfina ${ }^{(19,24)}$.

Com o objetivo de facilitar as pesquisas relacionadas às IM, autores como, Tatro ${ }^{(19)}$ e Bachmann ${ }^{(20)}$ sugeriram classificações quanto à significância clínica das IM de inúmeros medicamentos. Deste modo, esses autores avaliaram informações relativas ao início, a severidade e às evidências científicas (documentação) existentes quanto à ocorrência da IM.

Para Tatro ${ }^{(19)}$, quando se analisa uma determinada IM, o principal ponto é saber sua relevância clinica ou sua significância. Segundo Tatro (2005) "significância refere-se ao tipo e magnitude do efeito e, subseqüente, a necessidade de monitorização do paciente de alteração da terapia para evitar possíveis conseqüências adversas".

Os fatores que definem "significância clinica" incluem : nível, tempo de inicio do efeito da IM, potencial de severidade da IM, e a evidência científica relativa à ocorrência da IM na clínica. Deste modo, a classificação avalia significância clínica em cinco níveis, como ilustra a Figura 5.

O tempo de início dos efeitos clínicos de uma IM pode ajudar os profissionais a determinar a urgência do atendimento e introduzir, quando necessário, medidas preventivas para as conseqüências desta IM. O inicio de uma determinada IM pode ser rápido e lento ${ }^{(19)}$. 
Denomina-se inicio rápido aquele efeito que será evidenciado em 24 h após administração dos medicamentos. São necessárias ações imediatas para evitar os efeitos das interações. O inicio lento será evidenciado, dias ou semanas, após a administração dos medicamentos. Não é necessária ação corretiva imediata ${ }^{(19)}$.

O potencial de severidade de uma IM é importante para que haja uma avaliação do risco versus benefício da terapia. Na clínica, os efeitos negativos de uma IM podem ser evitados, por meio de ajuste posológico de um dos medicamentos ou modificação do aprazamento de horário da administração. São definidos três graus de severidade: maior, moderado e menor $^{(19)}$.

Na severidade classificada com maior, os efeitos decorrentes da IM ameaçam a vida do individuo, podendo causar danos permanentes. $\mathrm{Na}$ moderada, os efeitos da IM podem causar dano ao paciente ou aumentar o tempo de hospitalização. Na menor, os efeitos são leves e as conseqüências podem incomodar o individuo ou passarem desapercebidas. Todavia, não é necessário nenhum tratamento adicional ${ }^{(19)}$.

A evidência cientifica (documentação) determina o grau de confiança da informação relativa à resposta clínica decorrente da IM. A escala proposta pelo autor representa a avaliação de estudiosos sobre o tema acerca da qualidade e relevância clínica da literatura sobre a ocorrência de uma determinada $\mathrm{IM}^{(19)}$.

Para estabelecer os níveis de evidência cientifica (documentação) foram elaboradas cinco categorias, a saber : estabelecida, provável, suspeita, possível e improvável ${ }^{(19)}$.

A documentação na categoria estabelecida é inserida quando há provas por meio da ocorrência da IM em estudos bem controlados. É provável quando é típica, porém não comprovada clinicamente; suspeita se a IM pode ocorrer, se há algumas informações relativas ao evento, todavia é 
necessário maior número de estudos. Na categoria possível, a IM pode ocorrer, mas os dados são muito limitados e, improvável, quando não há nenhuma evidência de alteração dos efeitos clínicos no paciente ${ }^{(19)}$.

As IM classificadas como de documentação estabelecida, provável ou suspeita são consideradas bem justificadas e apresentam grau de significância "1", "2" ou " 3 ". Porém, as possíveis e improváveis são injustificadas, ou seja, apresentam evidências insuficientes para comprovar a existência da relevância clínica da $\mathrm{IM}^{(19)}$.

Figura 5 - Níveis de significância clínica das interações medicamentosas ${ }^{(19)}$.

\begin{tabular}{|c|l|l|}
\hline Nível & \multicolumn{1}{|c|}{ Severidade } & \multicolumn{1}{c|}{ Documentação } \\
\hline 1 & Maior & Bem documentada \\
\hline 2 & Moderada & Suspeita, provável ou bem documentada \\
\hline 3 & Menor & Suspeita, provável ou bem documentada \\
\hline 4 & Varia de maior a moderada & Possível, mas com documentação limitada \\
\hline 5 & $\begin{array}{l}\text { Menor } \\
\text { Qualquer }\end{array}$ & $\begin{array}{l}\text { Possível, mas com documentação limitada } \\
\text { Pouco provável, documentação limitada, sem } \\
\text { evidências. }\end{array}$ \\
\hline
\end{tabular}

De acordo com Bachmann ${ }^{(20)}$ as IM podem, também, ser classificadas em 5 níveis. Todavia este autor considera, especialmente, o risco da terapia combinada, a partir da severidade ou não da IM, obtida por meio da documentação existente na literatura, como ilustra a Figura 6. Ele, ainda, qualifica a natureza da IM de acordo com o inicio do efeito e o impacto da severidade.

O tempo de início do efeito refere-se ao momento inicial do aparecimento dos efeitos adversos, podendo ser imediatos (0-12 h); rápidos $(12-72 \mathrm{~h} \text { ) e lentos (tempo superior a } 72 \mathrm{~h})^{(20)}$.

No que se refere ao impacto da severidade, eles podem ser maior, moderado e menor. $O$ impacto denominado maior provoca efeitos, que 
podem resultar em morte, hospitalização, injúria permanente do paciente ou insucesso terapêutico. $O$ moderado, requer intervenções médicas para tratamento dos efeitos adversos. No impacto classificado como menor, os efeitos podem ser tolerados, na maioria dos casos, e não requerem intervenções médicas ${ }^{(20)}$.

Figura 6 - Níveis de risco da terapia combinada ${ }^{(20)}$

\begin{tabular}{|c|l|l|}
\hline Nível & \multicolumn{1}{|c|}{ Terapia combinada } & \multicolumn{1}{c|}{ Documentação } \\
\hline A & $\begin{array}{l}\text { Não há conhecimento de } \\
\text { ocorrência de IM }\end{array}$ & $\begin{array}{l}\text { Não há dados que demonstrem a existência } \\
\text { de IM entre os agentes. }\end{array}$ \\
\hline B & $\begin{array}{l}\text { Nenhuma conduta terapêutica } \\
\text { é necessária }\end{array}$ & $\begin{array}{l}\text { Os dados mostram que os agentes podem } \\
\text { interagir, porém as evidências são poucas. }\end{array}$ \\
\hline C & Monitorar a terapia & $\begin{array}{l}\text { Os dados mostram que os agentes podem } \\
\text { interagir. Os benefícios do uso concomitante } \\
\text { usualmente superam os riscos. Todavia, é } \\
\text { necessário manejo de efeitos adversos e o } \\
\text { ajuste de dose. }\end{array}$ \\
\hline D & $\begin{array}{l}\text { Considerar modificação da } \\
\text { terapia }\end{array}$ & $\begin{array}{l}\text { Os dados mostram que os agentes } \\
\text { interagem. Deverá ser realizada uma } \\
\text { avaliação cautelosa dos benefícios do uso } \\
\text { concomitante e implementação de ações } \\
\text { específicas para minimizar os efeitos tóxicos. } \\
\text { Além disso, deve ser considerada a escolha } \\
\text { de agentes alternativos. }\end{array}$ \\
\hline X & $\begin{array}{l}\text { Evitar a terapia combinada } \\
\text { com os agentes analisados }\end{array}$ & $\begin{array}{l}\text { Os dados mostram que existe interação e o } \\
\text { uso concomitante é contra-indicado. }\end{array}$ \\
\hline
\end{tabular}

\subsection{Justificativa do estudo}

A observação empírica do dia-a-dia na unidade de TMO tem mostrado alguns fatos que subsidiaram a construção do presente estudo.

Pacientes transplantados são expostos a protocolos de tratamentos prolongados, com inúmeros medicamentos, principalmente antimicrobianos, muitos, inclusive, com potencial interativo. Além disso, verifica-se que a questão das IM nesta classe especifica é pouco discutida pelas equipes profissionais, apesar de todos os pacientes utilizarem esses agentes terapêuticos. 
As pesquisas e estudos clínicos que permeiam o tema IM, estão na sua maioria, direcionados aos profissionais da área médica e farmacêutica, principalmente norte-americanos e europeus, não discutindo o assunto no âmbito da enfermagem.

A enfermeira, além de ser um dos profissionais mais envolvidos, diretamente, no processo da administração de medicamentos vem preocupando-se cada vez mais com a melhoria da qualidade da assistência, a redução de erros relacionados à prática, a segurança do paciente e desenvolvimento de pesquisas que respondam a inquietações cotidianas, tal como a questão das IM.

Assim, considerando-se que para os pacientes submetidos a TMO, a terapia farmacológica, principalmente antimicrobiana representa um dos principais pontos para o sucesso do procedimento, que as associações são utilizadas como importante estratégia terapêutica, mas que podem acarretar em IM, que sua ocorrência apresenta impacto na terapia, expondo, muitas vezes, o individuo a risco de vida, e que a enfermeira pode apresentar um papel importante na identificação dos efeitos decorrentes de IM, concebeuse o presente estudo. 
Objetivos 


\section{OBJETIVOS}

1 - Caracterizar o perfil terapêutico dos medicamentos utilizados pelos pacientes submetidos a TMO.

2 - Identificar as combinações existentes entre antimicrobianos potencialmente interativos e outros medicamentos decorrentes da co-administração em pacientes submetidos a TMO.

3 - Analisar, a partir das combinações identificadas, as interações medicamentosas potenciais quanto aos seguintes aspectos: tipo de interações, nível de severidade, evidências cientificas, implicações clínicas potenciais, tempo de inicio dos efeitos e nível de risco de terapia combinada. 
Casuística e Método 


\section{CASUÍSTICA E MÉTODO}

\subsection{Tipo de estudo}

De acordo com a classificação de Polit et al $^{(50)}$, trata-se de uma pesquisa descritiva e exploratória, de campo, que foi desenvolvida em duas etapas.

A primeira etapa da pesquisa foi descritiva, cujo propósito foi descrever aspectos relativos à terapia farmacológica e as combinações existentes entre antimicrobianos potencialmente interativos e outros medicamentos decorrentes da co-administração em pacientes submetidos a TMO. Para isso, utilizaram-se informações de documentos - prontuário dos pacientes - existentes no próprio campo de pesquisa. A segunda etapa foi exploratória, quando se explorou as dimensões das combinações e das IM identificadas.

\subsection{Local de estudo}

O estudo foi realizado no setor de TMO do Instituto do Coração do Hospital das Clínicas da Faculdade de Medicina da Universidade de São Paulo (INCOR-HCFMUSP), localizado no município de São Paulo, que atende pacientes do SUS (Sistema Único de Saúde).

A unidade de TMO do INCOR-HCFMUSP foi inaugurada em outubro de 2000 com quatro leitos, sendo ampliados para seis no ano de 2004. O número de transplantes realizados nesta unidade, no período de 2000 a 2005 foi crescente, aumentando em 42\%, de 74 para 128 transplantes, após a ampliação do número de leitos (Figura 7) 
Figura 7 - Transplantes de medula óssea realizados no INCOR-HC-FMUSP. São Paulo, 2000-2005

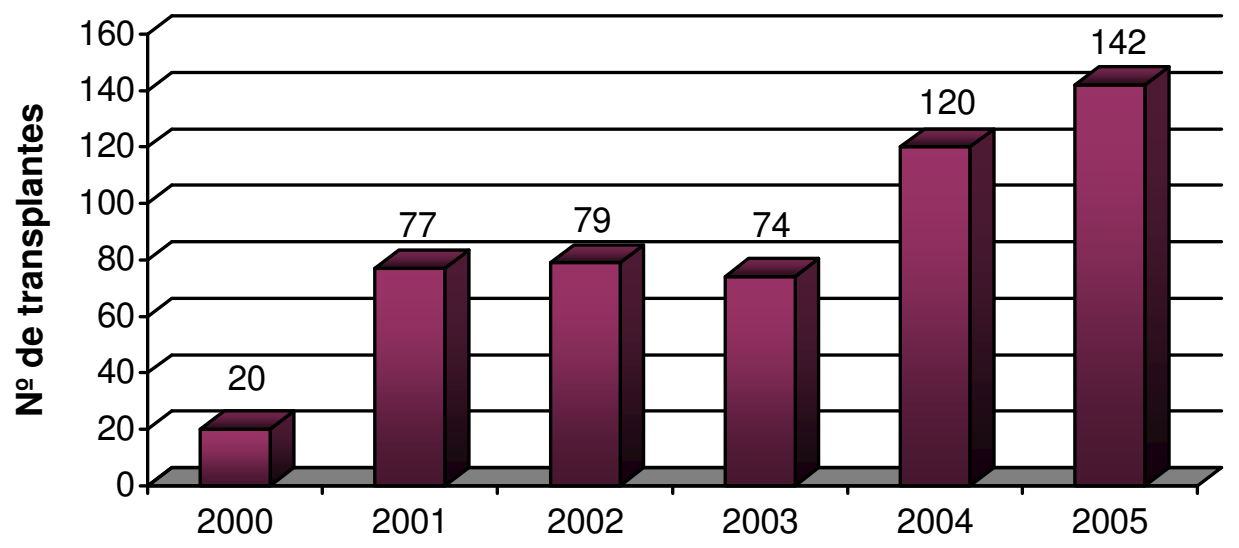

$\mathrm{Na}$ unidade de TMO, a assistência de enfermagem é integral, havendo no serviço a Sistematização da Assistência de Enfermagem (SAE), que é realizada por cinco enfermeiras e cinco auxiliares de enfermagem, distribuídos em três turnos (manhã, tarde e noite).

No que se refere ao aprazamento dos horários da prescrição médica, cabe destacar que é uma atividade exclusiva da enfermeira responsável pelo plantão. Todavia, a administração de medicamentos é desenvolvida por todos os integrantes da equipe de enfermagem, com exceção dos quimioterápicos antineoplásicos, que são restritos às enfermeiras.

As prescrições dos medicamentos são realizadas por médicos assistentes da equipe de TMO do HC-FMUSP, o quais fazem escala com esquema de rodízio para atendimento dos pacientes.

A prescrição médica com vigência de 24 h é feita através de um sistema informatizado utilizado na Instituição "Oracle", que possibilita o aprazamento de, alguns, medicamentos em horários padronizados pelo 
serviço, que são alterados manualmente pelas enfermeiras responsáveis pela organização das atividades de enfermagem.

Nesta unidade de TMO, os pacientes permanecem internados por um período de 12 a 19 dias para realização do procedimento, dependendo do tipo de transplante. A alta hospitalar, freqüentemente, ocorre no $1^{\circ}$ dia pós TMO $(+1)$. Estes pacientes com alta continuam a terapia em ambulatório no HC-FMUSP.

\subsection{Casuística}

A casuística foi constituída de 70 prescrições médicas de pacientes que se encontravam no dia -1 da pré-infusão de medula óssea, independente de raça, diagnóstico, idade ou sexo, hospitalizados no período de janeiro a julho de 2005. A escolha do dia -1 deveu-se ao fato de que a introdução dos antimicrobianos profiláticos inicia-se nesta data específica. Foram excluídos os pacientes transferidos para a unidade de terapia intensiva (UTI) ou aqueles que evoluíram para óbito no dia do estudo.

\subsection{Coleta de dados}

O projeto de pesquisa foi aprovado pela Comissão Científica e Comitê de Ética da Instituição (Anexo A).

\subsubsection{Operacionalização}

A coleta de dados foi composta de duas fases, sendo que para ambas utilizou-se fonte documental de informações.

Na primeira fase consultou-se o prontuário do paciente, buscandose identificar o perfil terapêutico dos medicamentos utilizados pelos pacientes e as combinações existentes entre antimicrobianos potencialmente interativos e outros medicamentos. Para traçar o perfil terapêutico dos medicamentos utilizou-se a classificação Alfa do 
GUIAMED ${ }^{(51)}$, proposta por Zanini \& Oga, que contempla os aspectos alfabéticos, terapêuticos e mnemônicos (Anexo B). Deste modo, os medicamentos foram listados e classificados em oito categorias a saber: analgesia (A), cardiovascular (C), digestivo (D), hormônios $(H)$, imunologia e alergia $(\mathrm{I})$, neurologia $(\mathrm{N})$, psiquiatria $(\mathrm{P})$ e quimioterapia $(\mathrm{Q})$.

O potencial de interação dos medicamentos foi analisado segundo Grahame-Smith \& Aronson $^{(22)}$, que classificam os medicamentos em precipitador e objeto. As características farmacológicas dos medicamentos foram listadas a partir dos dados de farmacocinética existentes nas monografias presentes na base de dados Micromedex ${ }^{(52)}$. Esta base foi consultada através do portal de periódicos CAPES, com acesso on line restrito.

Os dados obtidos na fase inicial subsidiaram a coleta da próxima etapa em que se consultou a literatura especializada ${ }^{(19,20)}$, para realizar análise das combinações existentes e as IM potenciais, as quais foram analisadas duas a duas.

Para cada uma das fases do estudo utilizou-se instrumento de coleta de dados específico.

O sumário das fases do estudo com as respectivas atividades desenvolvidas encontra-se ilustrado na Figura 8. 
Figura 8 - Sumário das etapas seguidas na coleta de dados.

\section{FASE I}

\section{Consulta ao prontuário,}

Guiamed, Grahame-Smith \& Aronson e Micromedex

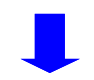

Perfil da terapia farmacológica

1 - Número e nome dos medicamentos

2 - Classificação terapêutica

3 - Potencial interativo dos medicamentos

4 - Características farmacológicas

5 - Combinações entre antimicrobianos potencialmente interativos e outras medicamentos

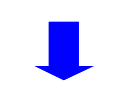

\section{FASE II}

Consulta a literatura

Tatro, Bachmann e Micromedex

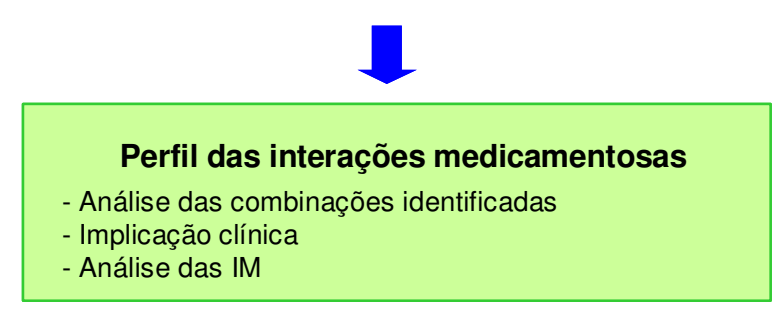

\subsubsection{Instrumentos}

Para obterem-se as informações necessárias ao estudo, foram elaborados dois instrumentos.

O instrumento utilizado para coleta de dados dos prontuários denominado "Ficha do prontuário" (Anexo C) foi composto por duas partes: a primeira referente à identificação dos pacientes, contendo as seguintes variáveis: idade, sexo, diagnóstico, tipo de TMO, tipo de cateter central utilizado. A segunda, relativa à prescrição de medicamentos constituída das 
variáveis: nome genérico e comercial do medicamento, via e horário de administração.

O outro instrumento utilizado para coleta de dados da literatura (Anexo D) foi composto por variáveis referentes ao tipo de IM (farmacocinética e farmacodinâmica), nível de severidade, evidência cientifica, implicações clínicas potenciais, tempo de inicio do efeito e nível de risco de terapia combinada.

\subsubsection{Classificação das IM}

Para a classificação das IM utilizou-se Tatro $^{(19)}$ e Bachmann ${ }^{(20)}$ autores clássicos da área específica de IM. A escolha desses dois autores ocorreu no intuito de ampliar a analise das IM, tendo em vista que o primeiro discute com vagar a IM sob vários aspectos, o segundo também, no entanto, acrescenta o nível de risco da terapia combinada, fator que do ponto de vista prático é fundamental. A busca pelas informações nesses compêndios ocorreu de forma manual.

As IM potenciais foram classificadas de acordo com nível de severidade em maior, moderado e menor (Figura 9) e acerca da evidência cientifica (Figura 10) ${ }^{(19)}$. Cabe destacar que a evidência não se encontra relacionada à severidade, prevalência ou incidência da IM. Analisaram-se as IM, também, segundo o risco da terapia combinada (Figura 11) ${ }^{(20)}$.

Figura 9 - Interações medicamentosas segundo o nível de severidade ${ }^{(19)}$

\begin{tabular}{|l|l|}
\hline Nível de severidade & \multicolumn{1}{|c|}{ Efeito potencial } \\
\hline 1 (Maior) & $\begin{array}{l}\text { O efeito adverso decorrente da IM pode resultar em morte, } \\
\text { hospitalização, injúria permanente do paciente ou insucesso } \\
\text { terapêutico. }\end{array}$ \\
\hline 2 (moderada) & $\begin{array}{l}\text { O efeito adverso decorrente da IM pode causar dano e requer } \\
\text { intervenções e tratamento médico }\end{array}$ \\
\hline 3 (menor) & $\begin{array}{l}\text { O efeito decorrente da IM pode ser tolerado, é pequeno ou sem } \\
\text { manifestação clinica, e não requer tratamento } .\end{array}$ \\
\hline
\end{tabular}


Figura 10 - Interações medicamentosas segundo o nível de evidência cientifica ${ }^{(19)}$

\begin{tabular}{|l|l|}
\hline Nível de evidência & \multicolumn{1}{|c|}{ Tipo de informação cientifica } \\
\hline 1 (Estabelecida) & Efeito adverso confirmado por ensaios clinicos \\
\hline 2 (provável) & $\begin{array}{l}\text { Efeito adverso com alta probabilidade de ocorrência mas sem } \\
\text { ensaios clínicos randomizados }\end{array}$ \\
\hline 3 (suspeita) & $\begin{array}{l}\text { Efeito adverso possivel de ocorrer, informações derivam-se de } \\
\text { relatos de caso }\end{array}$ \\
\hline 4 (possível) & Efeito adverso pode ocorrer mas as informações são escassas \\
\hline 5 (improvável) & Efeito adverso pode teoricamente ocorrer \\
\hline
\end{tabular}

Figura 11 - Interações medicamentosas segundo o nível de risco da terapia combinada ${ }^{(20)}$

\begin{tabular}{|l|l|}
\hline \multicolumn{1}{|c|}{ Nível } & \multicolumn{1}{c|}{ Terapia combinada } \\
\hline A & Não há conhecimento de ocorrência de IM \\
\hline B & Nenhuma conduta terapêutica é necessária \\
\hline C & Monitorar a terapia \\
\hline D & Considerar modificação da terapia \\
\hline X & Evitar a terapia combinada com os agentes analisados \\
\hline
\end{tabular}

\subsection{Análise dos dados}

Para análise dos dados utilizou-se Microsoft Excel versão XP e o programa SPSS versão 13.0 .

Utilizou-se análise descritiva (freqüência absoluta e relativa, média, desvio-padrão, mediana, mínimo e máximo) para os dados relativos ao perfil da terapia, das combinações e das IM.

Para verificar-se a associação entre as variáveis independentes (sexo, idade, tipo de TMO e número de medicamentos administrados) e dependente (IM) utilizou-se regressão logística multivariada, ajustada por sexo e idade.

O nível de significância considerado foi $\mathrm{p}<0,05$. 


\section{RESULTADOS}

\subsection{Caracterização dos pacientes quanto às variáveis demográfico- clínicas e ao perfil de aprazamento dos horários da prescrição médica.}

No que se diz respeito às características demográfico-clínicas da amostra verificou-se que houve predomínio de pacientes do sexo masculino $(52,9 \%)$, com diagnóstico de linfoma $(38,6 \%)$ e submetidos a TMO do tipo autólogo $(65,7 \%)$. Todos os pacientes utilizavam cateter venoso central, sendo o Hickman (60\%) o mais utilizado (Tabela 1).

Tabela 1 - Distribuição da amostra segundo sexo, diagnósticos e tipo de transplante de medula óssea. São Paulo, 2005.

\begin{tabular}{|c|c|c|}
\hline \multirow{2}{*}{ Características } & \multicolumn{2}{|c|}{ Pacientes } \\
\hline & $\mathbf{N}$ & $\%$ \\
\hline \multicolumn{3}{|l|}{ Sexo } \\
\hline Masculino & 37 & 52,9 \\
\hline Feminino & 33 & 47,1 \\
\hline \multicolumn{3}{|l|}{ Idade } \\
\hline$<$ ou igual 19 & 12 & 17,1 \\
\hline 20 a 29 & 16 & 22,9 \\
\hline 30 a 39 & 9 & 12,8 \\
\hline 40 a 49 & 13 & 18,6 \\
\hline > ou igual 50 & 20 & 28,6 \\
\hline \multicolumn{3}{|l|}{ Diagnóstico } \\
\hline Linfomas $\left(\mathrm{LH}^{*} / \mathrm{LNH}^{*}\right)$ & 27 & 38,6 \\
\hline Leucemias ( LMA*/LMC*/LLA*) & 21 & 30,0 \\
\hline Mieloma Múltiplo & 17 & 24,3 \\
\hline Mielodisplasia/|Mielofibrose & 3 & 4,3 \\
\hline Anemia & 1 & 1,4 \\
\hline Câncer de testículo & 1 & 1,4 \\
\hline \multicolumn{3}{|l|}{ Tipo de TMO } \\
\hline Autólogo & 46 & 65,7 \\
\hline Alogênico & 24 & 34,3 \\
\hline \multicolumn{3}{|l|}{ Tipo de cateter } \\
\hline Hickman & 42 & 60,0 \\
\hline Permicath & 24 & 34,3 \\
\hline Port- a-cath & 4 & 5,7 \\
\hline
\end{tabular}


A média de idade dos pacientes foi de 37,31 (DP 15,95) e a média de medicamentos administrados nas 24 hs foi 7,97(DP 2,34) (Tabela 2).

Tabela 2 - Distribuição dos pacientes segundo variáveis quantitativas. São Paulo, 2005.

\begin{tabular}{lccccc}
\hline \multicolumn{1}{c}{ Variáveis } & Média & Mediana & $\begin{array}{c}\text { Desvio } \\
\text { Padrão }\end{array}$ & Mínimo & Máximo \\
\hline Idade & 37,31 & 36,5 & 15,95 & 9 & 66 \\
$\begin{array}{l}\text { № de medicamentos } \\
\text { utilizados nas 24hs }\end{array}$ & 7,97 & 8,0 & 2,34 & 4 & 16 \\
\hline
\end{tabular}

O número de agentes administrados por paciente variou de 4 a 16, sendo que $35,7 \%(n=25)$ dos pacientes receberam de 6 a 7 (Figura 12)

Figura 12 - Distribuição dos pacientes segundo medicamentos administrados em 24h. São Paulo, 2005.

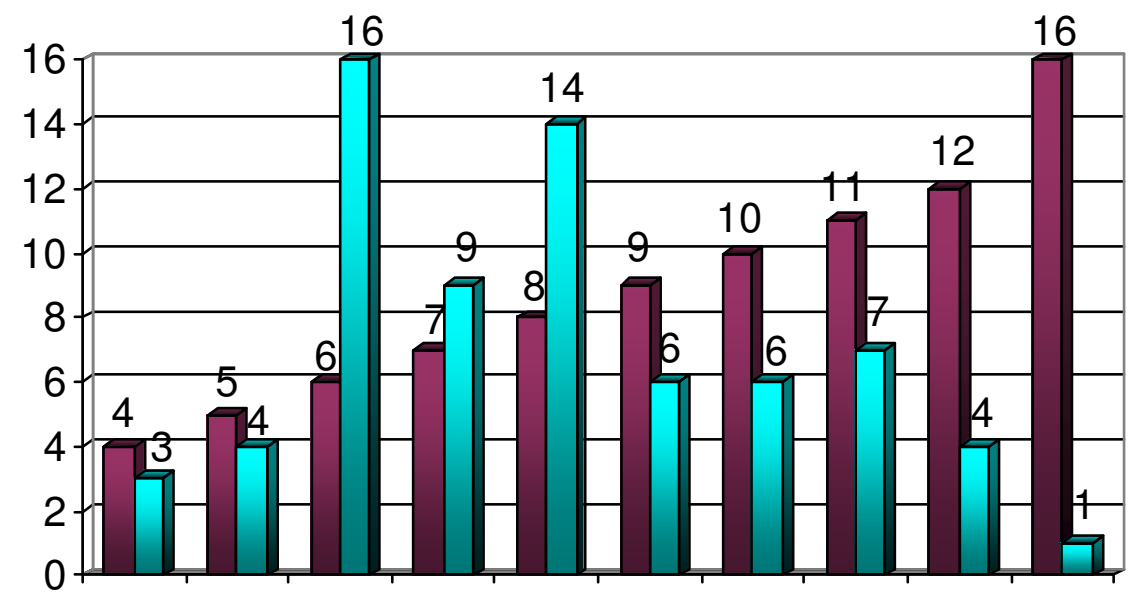

$\square$ № de medicamentos $\square$ № de pacientes 
Quanto ao perfil do aprazamento dos medicamentos observou-se que no período da manhã $100 \%$ dos pacientes foram medicados às $10 \mathrm{~h}$ e $85,7 \%(\mathrm{n}=60)$ às $12 \mathrm{~h}$. À tarde, verificou-se uma concentração de medicamentos aprazados para as $17 \mathrm{~h}(67,1 \%)$ e $18 \mathrm{~h}(95,7 \%)$. No noturno, concentrou-se em dois horários, sendo $100 \%$ às $22 \mathrm{~h}$ e $98,6 \%$ às $06 \mathrm{~h}$ (Figura 13).

Figura 13 - Distribuição dos pacientes segundo horários de medicamentos aprazados. São Paulo, 2005.

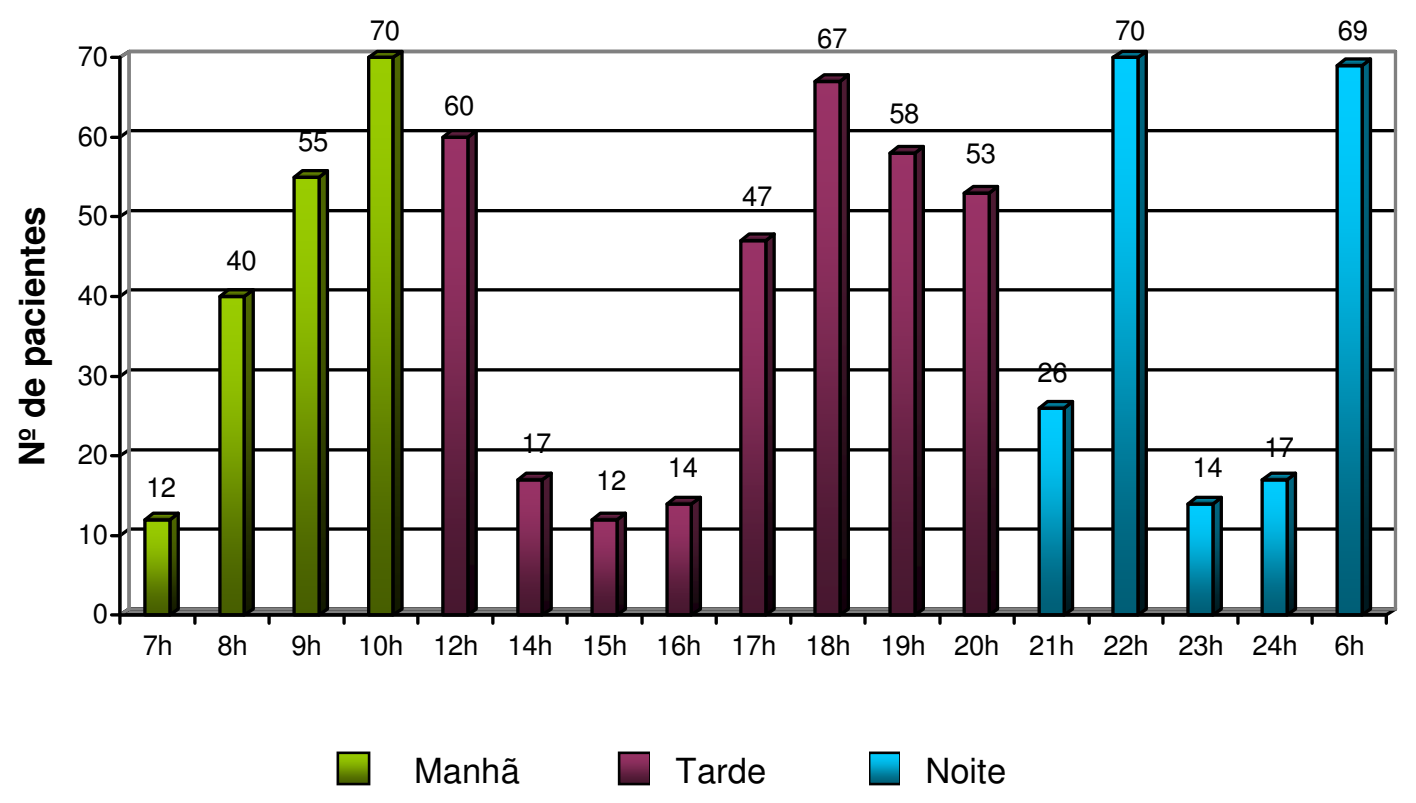

Observou-se que às médias de medicamentos aprazados, nos horários das $10 \mathrm{~h} \quad(3,14)$ e $22 \mathrm{~h}(2,90)$ foram superiores a outros, havendo inclusive nestes mesmos horários, o maior número de medicamentos administrados de modo concomitante $(n=12)$ (Tabela 3 e Figura 14). 
Tabela 3 - Análise descritiva dos medicamentos utilizados pelos pacientes submetidos a transplante de medula óssea, segundo respectivos horários de aprazamento. São Paulo, 2005.

\begin{tabular}{|c|c|c|c|c|c|}
\hline \multirow{2}{*}{ HORÁRIO } & \multicolumn{5}{|c|}{ MEDICAMENTOS } \\
\hline & Média & Mediana & DP & Min & Max \\
\hline 06 & 2,51 & 2,00 & 0,92 & 0 & 6 \\
\hline 07 & ,23 & 0 & 0,54 & 0 & 2 \\
\hline 08 & ,94 & 1,00 & 0,93 & 0 & 3 \\
\hline 09 & 1,41 & 2,00 & 1,00 & 0 & 5 \\
\hline 10 & 3,14 & 3,00 & 1,26 & 1 & 9 \\
\hline 12 & 1,26 & 1,00 & 0,79 & 0 & 4 \\
\hline 13 & ,24 & 0 & 0,43 & 0 & 1 \\
\hline 15 &, 17 & 0 & 0,38 & 0 & 1 \\
\hline 16 & ,24 & 0 & 0,52 & 0 & 2 \\
\hline 17 & 1,19 & 1,00 & 1,32 & 0 & 6 \\
\hline 18 & 2,63 & 3,00 & 1,29 & 0 & 6 \\
\hline 19 & 1,53 & 2,00 & 0,92 & 0 & 3 \\
\hline 20 & 1,36 & 1,00 & 0,99 & 0 & 3 \\
\hline 21 & ,63 & 0 & 0,95 & 0 & 3 \\
\hline 22 & 2,90 & 2,00 & 1,70 & 1 & 12 \\
\hline 23 & 0,33 & 0 & 0,75 & 0 & 3 \\
\hline 24 & 1,51 & 2,00 & 0,79 & 0 & 3 \\
\hline
\end{tabular}


Figura 14 - Média de medicamentos aprazados nos horários. São Paulo, 2005.

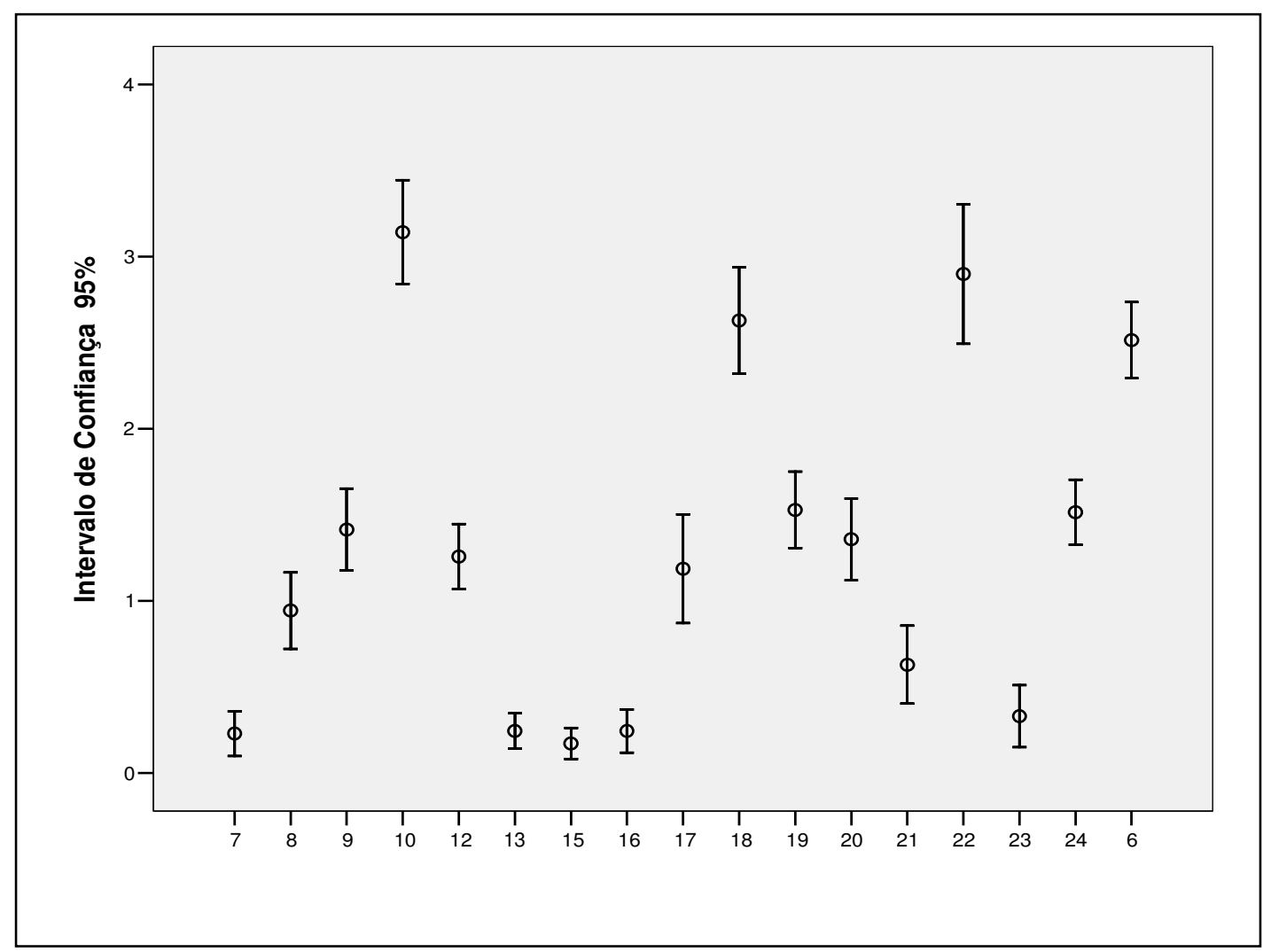

\subsection{Perfil da terapia farmacológica}

No perfil da terapia farmacológica dos pacientes, na fase de condicionamento do TMO, foram identificados 33 medicamentos distintos pertencentes a 8 classes terapêuticas. As classes dos quimioterápicos $(34,0 \%)$, da analgesia $(21,0 \%)$ e dos agentes que atuam no sistema digestório (15,0 \%) foram as que apresentaram maiores freqüências (Figura 15). 
Figura 15 - Medicamentos utilizados por pacientes submetidos a transplante de medula óssea segundo classificação terapêutica Alfa. São Paulo, 2005.

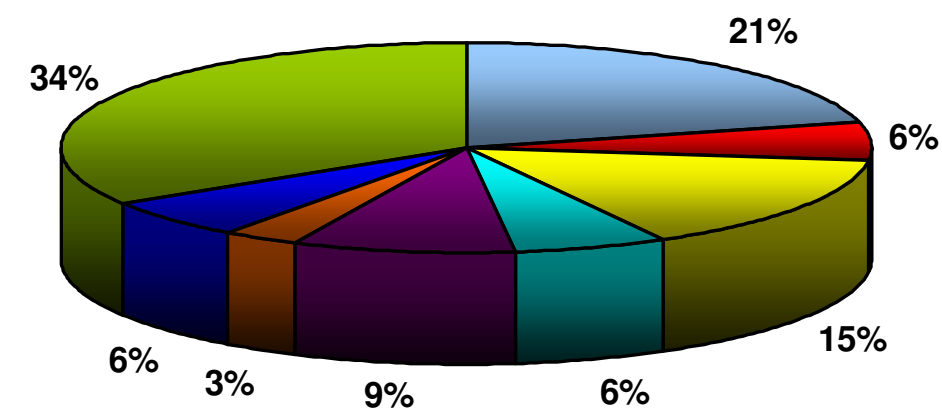

\begin{tabular}{|c|c|c|c|}
\hline $\begin{array}{l}\square \text { Analgesia } \\
\square \text { Imunologia }\end{array}$ & $\begin{array}{l}\square \text { Cardiovascular } \\
\square \text { Neurologia }\end{array}$ & $\begin{array}{l}\square \text { Digestório } \\
\square \text { Psiquiatria }\end{array}$ & $\begin{array}{l}\square \text { Hormônios } \\
\square \text { Quimioterapia }\end{array}$ \\
\hline
\end{tabular}

$\mathrm{Na}$ classe da analgesia a dipirona (15,7\%) destacou-se como analgésico e antitérmico, e o alopurinol (15,7\%) como anti-gotoso. Na classe cardiovascular a furosemida (38,6\%) foi a mais utilizada, e dentre os agentes que afetaram o sistema digestório, os de maior freqüência foram a ondansetrona (97,1\%) e o omeprazol (88,6\%). Na classe dos quimioterápícos sobressaíram o aciclovir $(100,0 \%)$, a cefepima $(47,1 \%)$ e 0 fluconazol (45,7\%) (Tabela 4).

No que se diz respeito à via de administração dos medicamentos observou-se que $66.7 \%(n=22)$ foram utilizados por via intravenosa, $30.0 \%$ $(n=10)$ por via oral e $3.3 \%(n=1)$ por via transdérmica. 
Rosimeire Barbosa Fonseca Guastaldi

Tabela 4 - Distribuição dos medicamentos utilizados em transplante de medula óssea segundo classificação terapêutica Alfa, nome genérico e número de pacientes submetidos à terapia. São Paulo, 2005.

\begin{tabular}{|c|c|c|c|}
\hline \multirow{2}{*}{ Classificação Alfa } & \multirow{2}{*}{ Medicamentos } & \multicolumn{2}{|c|}{ Pacientes } \\
\hline & & $\mathbf{N}$ & \\
\hline \multicolumn{4}{|l|}{ A - Analgesia } \\
\hline Analgésico e antitérmico & $\begin{array}{l}\text { dipirona } \\
\text { paracetamol }\end{array}$ & $\begin{array}{r}11 \\
6\end{array}$ & $\begin{array}{r}15,7 \\
8,6\end{array}$ \\
\hline Antiinflamatórios não esteroidais e anti-reumáticos & $\begin{array}{l}\text { alopurinol } \\
\text { naproxeno }\end{array}$ & $\begin{array}{r}11 \\
3\end{array}$ & $\begin{array}{r}15,7 \\
4,3\end{array}$ \\
\hline Antiespasmódicos & Hioscina & 3 & 4,3 \\
\hline Analgésicos opióides & $\begin{array}{l}\text { morfina } \\
\text { fentanil }\end{array}$ & $\begin{array}{l}3 \\
3\end{array}$ & $\begin{array}{l}4,3 \\
4,3\end{array}$ \\
\hline \multicolumn{4}{|l|}{ C - Cardiovascular } \\
\hline $\begin{array}{l}\text { Diurético } \\
\text { Antihipertensivo }\end{array}$ & $\begin{array}{l}\text { furosemida } \\
\text { atenolol }\end{array}$ & $\begin{array}{r}27 \\
1\end{array}$ & $\begin{array}{r}38,6 \\
1,4\end{array}$ \\
\hline \multicolumn{4}{|l|}{ D - Digestivo } \\
\hline Antiácidos/ neutralizantes & Omeprazol & 62 & 88,6 \\
\hline Antieméticos & $\begin{array}{l}\text { ondansetronaa } \\
\text { dimenidrinato } \\
\text { metoclopramida }\end{array}$ & $\begin{array}{l}68 \\
53 \\
45\end{array}$ & $\begin{array}{l}97,1 \\
75,7 \\
64,3\end{array}$ \\
\hline $\begin{array}{l}\text { Antiulcerosos } \\
\text { H - Hormônios }\end{array}$ & Ranitidina & 4 & 5,7 \\
\hline Corticosteróides & $\begin{array}{l}\text { dexametasona } \\
\text { hidrocortisona }\end{array}$ & $\begin{array}{r}24 \\
2\end{array}$ & $\begin{array}{r}34,3 \\
2,9\end{array}$ \\
\hline \multicolumn{4}{|l|}{ I - Imunologia/ Alergias } \\
\hline Antialérgicos & $\begin{array}{l}\text { difenidramina } \\
\text { hidroxizina }\end{array}$ & $\begin{array}{l}9 \\
1\end{array}$ & $\begin{array}{r}12,9 \\
1,4\end{array}$ \\
\hline Imunosupressores & Ciclosporina & 22 & 31,4 \\
\hline \multicolumn{4}{|l|}{ N - Neurologia } \\
\hline Anticonvulsivantes & Fenitoína & 15 & 21,4 \\
\hline \multicolumn{4}{|l|}{ P - Psiquiatria } \\
\hline Sedativos e ansiolíticos & Diazepam & 32 & 45,7 \\
\hline Antidepressivos e analépticos & Sertralina & 3 & 4,3 \\
\hline \multicolumn{4}{|l|}{ Q - Quimioterapia } \\
\hline Antivirais & Aciclovir & 70 & 100,0 \\
\hline Cefalosporinas & Cefepima & 33 & 47,1 \\
\hline $\begin{array}{l}\text { Antimicóticos } \\
\text { Sulfas }\end{array}$ & $\begin{array}{l}\text { Fluconazol } \\
\text { sulfametoxazol + trimetoprima }\end{array}$ & $\begin{array}{r}32 \\
9\end{array}$ & $\begin{array}{l}45,7 \\
12,9\end{array}$ \\
\hline Macrolídeos & $\begin{array}{l}\text { teicoplamina } \\
\text { vancomicina }\end{array}$ & $\begin{array}{l}7 \\
1\end{array}$ & $\begin{array}{r}10,0 \\
1,4\end{array}$ \\
\hline Quinolônicos & $\begin{array}{l}\text { levofloxacina } \\
\text { ciprofloxacina }\end{array}$ & $\begin{array}{l}7 \\
1\end{array}$ & $\begin{array}{r}10,0 \\
1,4\end{array}$ \\
\hline Carbapenens & Meropenem & 3 & 4,3 \\
\hline Antineoplásico & $\begin{array}{l}\text { Melfalano } \\
\text { Ciclofosfamida }\end{array}$ & $\begin{array}{r}28 \\
1 \\
\end{array}$ & $\begin{array}{r}40,0 \\
1,4 \\
\end{array}$ \\
\hline
\end{tabular}


Quanto ao potencial para IM, observou-se que $72,7 \%(n=24)$ dos agentes apresentaram características que predispunham a ocorrência de IMs (alopurinol, naproxeno, morfina, fentanil, furosemida, omeprazol, ondansetrona, atenolol, metoclopramida, ranitidina, hidrocortisona, dexametasona, ciclosporina, fenitoina, diazepam, sertralina, fluconazol, sulfametoxazol+trimetoprima, teicoplamina, vancomincina, levofloxacina, ciprofloxacina, ciclofosfamida e melfalano), e 27,3\% ( $n=9)$ não apresentaram tais propriedades (dipirona, paracetamol, difenidramina, dimenidrinato, cefepima, hidroxizina, hioscina, aciclovir, meropenem) (Tabela 5).

Tabela 5 - Distribuição dos medicamentos utilizados por pacientes submetidos a transplante de medula óssea segundo potencial interativo. São Paulo, 2005.

\begin{tabular}{lcc}
\hline Potencial interativo & N & Medicamentos \\
\hline Sim & 24 & 72,7 \\
Não & 9 & 27,3 \\
\hline Total & 33 & $\mathbf{1 0 0 , 0}$ \\
\hline
\end{tabular}

Entre os medicamentos que apresentaram potencial interativo $79,2 \%(n=19)$ foram classificados como precipitadores (alopurinol, naproxeno, furosemida, omeprazol, ondansetrona, metoclopramida, ranitidina, hidrocortisona, dexametasona, fenitoína, diazepam, sertralina, fluconazol, sulfametoxazol+trimetoprima, teicoplamina, vancomincina, levofloxacina, ciprofloxacina e ciclofosfamida) e $20,8 \%$ ( $n=5)$ como objeto (morfina, fentanil, atenolol, ciclosporina e melfalano). Dentre estes, 16,7\% $(\mathrm{n}=4)$ apresentaram características de precipitadores e objeto (vancomincina, ciclofosfamida, metoclopramida e fenitoina) (Tabela 6). 
Tabela 6 - Distribuição dos medicamentos utilizados por pacientes submetidos a transplante de medula óssea segundo classificação . São Paulo, 2005.

\begin{tabular}{|c|c|c|}
\hline \multirow{2}{*}{ Classificação } & \multicolumn{2}{|c|}{ Medicamentos } \\
\hline & $\mathbf{N}$ & $\%$ \\
\hline Precipitador & 19 & 79,2 \\
\hline Objeto & 5 & 20,8 \\
\hline Total & 24 & 100,0 \\
\hline
\end{tabular}

Quanto à análise das características farmacológicas que predispunham as IM verificou-se que $66,8 \%$ dos medicamentos afetaram o metabolismo hepático inibindo-o $(46,0 \%)$ ou estimulando-o $(20,8 \%)$ (Tabela 7).

Tabela 7 - Distribuição dos medicamentos utilizados por pacientes submetidos a transplante de medula óssea, segundo características farmacológicas que predispõem a interação medicamentosa . São Paulo, 2005.

\section{Características farmacológicas}

\section{Medicamentos}

$\mathbf{N}$

$\%$

Inibidores enzimáticos

alopurinol, omeprazol, ciprofloxacina, diazepam, fluconazol, levofloxacina, metoclopramida, ondansetrona, ranitidina,

sertralina, sulfametoxazol+trimetoprima

\section{Indutores enzimáticos}

dexametasona, hidrocortisona, omeprazol, fenitoina ciclofosfamida.

\section{Alta ligação à proteína plasmática}

naproxeno, teicoplamina

Afeta clerance renal

furosemida, vancomicina

Ação no sistema nervoso central

morfina, fentanil

Estreito-indice terapêutico

atenolol, ciclosporina 
Entre os quimioterápicos antimicrobianos $66,7 \%(n=6)$ apresentaram características potencialmente interativas (fluconazol, sulfametoxazol+trimetoprima, teicoplamina, vancomicina, levofloxacina e ciprofloxacina), enquanto $33,3 \%$ ( $n=3$ ) não (cefepima, aciclovir, meropenem) (Tabela 8).

Tabela 8 - Distribuição dos quimioterápicos antimicrobianos utilizados por pacientes submetidos a transplante de medula óssea segundo potencial interativo. São Paulo, 2005.

\begin{tabular}{lcc}
\hline & Potencial interativo & \multicolumn{2}{c}{ Antimicrobianos } \\
Sim & N & $\%$ \\
Não & 6 & 66,7 \\
Total & 3 & 33,3 \\
\hline
\end{tabular}

Quanto às características farmacológicas dos antimicrobianos que propiciaram a ocorrência de IM 66,6\% eram inibidores enzimáticos (Tabela 9).

Tabela 9 - Distribuição dos quimioterápicos antimicrobianos utilizados por pacientes submetidos a transplante de medula óssea, segundo características farmacológicas que predispõem a interação medicamentosa . São Paulo, 2005.

\section{Características farmacológicas}

Inibidores enzimáticos

ciprofloxacina, fluconazol, levofloxacina, sulfametoxazol+trimetoprima

Antimicrobianos

$\mathbf{N}$

4

Alta ligação às proteínas plasmáticas teicolamina

Afeta o clerance real vancomicina 


\subsection{Perfil das combinações entre antimicrobianos potencialmente interativos e outros medicamentos}

A análise das IM potenciais dos antimicrobianos incluiu basicamente aqueles que inibiam o sistema enzimático (66,7\%), uma vez que a vancomicina e teicoplamina não apresentaram combinações que resultaram em IM potencial.

Verificou-se que metade da amostra $(n=35)$ foi exposta a IM potencias decorrentes das combinações de antimicrobianos com outros medicamentos. Entre os antimicrobianos destacou-se o fluconazol com o maior número de combinações $(85,7 \%)$, chegando inclusive a combinar-se com 5 medicamentos distintos. A ciprofloxacina combinou-se com 3 medicamentos distintos, apesar de ter ocorrido num único paciente. No que se refere ao fluconazol, observou-se que do total de pacientes $(n=32)$ que usaram 93,7\% ( $n=30)$ apresentou combinações que resultaram em IM (Tabela 10). 
Tabela 10 - Distribuição dos pacientes submetidos a transplante de medula óssea, segundo exposição às combinações existentes entre antimicrobianos potencialmente interativos e outros medicamentos. São Paulo, 2005.

\begin{tabular}{|c|c|c|}
\hline \multirow{2}{*}{ Combinações } & \multicolumn{2}{|c|}{$\begin{array}{c}\text { Pacientes } \\
(\mathrm{n}=35)\end{array}$} \\
\hline & $\mathbf{N}$ & $\%$ \\
\hline Fluconazol + diazepam + ciclosporina + dexametasona + sertralina + omeprazol & 1 & 2,9 \\
\hline Fluconazol + ciclosporina + fenitoína + dexametasona + omeprazol & 3 & 8,5 \\
\hline Fluconazol + diazepam + ciclosporina + omeprazol & 2 & 5,7 \\
\hline Fluconazol + diazepam + dexametasona + omeprazol & 2 & 5,7 \\
\hline Fluconazol + dexametasona + omeprazol + ciclosporina & 1 & 2,9 \\
\hline Fluconazol + diazepam + omeprazol & 8 & 22,9 \\
\hline Fluconazol + dexametasona + omeprazol & 4 & 11,4 \\
\hline Fluconazol + ciclosporina + omeprazol & 4 & 11,4 \\
\hline Fluconazol + omeprazol & 3 & 8,5 \\
\hline Fluconazol + ciclofosfamida & 1 & 2,9 \\
\hline Fluconazol + sertralina & 1 & 2,9 \\
\hline Total 1 (Fluconazol) & 30 & \\
\hline Sulfametoxazol+trimetoprima + ciclosporina & 2 & 5,7 \\
\hline Sulfametoxazol+trimetoprima + fenitoína & 2 & 5,7 \\
\hline Total 2 (Sulfametoxazol+trimetoprima ) & 4 & \\
\hline Ciprofloxacina + dexametasona + diazepam + ciclofosfamida & 1 & 2,9 \\
\hline Total 3 (Ciprofloxacina) & 1 & \\
\hline Total $(1+2+3)$ & 35 & 100,0 \\
\hline
\end{tabular}

A análise das IM das próximas tabelas foi feita considerando-se apenas 2 agentes (medicamento-medicamento).

$\mathrm{Na}$ Tabela 11, observa-se que o fluconazol apresentou 7 combinações distintas, destacando-se que $40,0 \%$ da amostra recebeu fluconazol + omeprazol, e 18,5\% o fluconazol + diazepam. 
Tabela 11 - Distribuição dos pacientes submetidos a transplante de medula óssea segundo exposição às interações medicamentosas potenciais do fluconazol. São Paulo, 2005.

\begin{tabular}{lcc}
\hline Interação medicamentosa potencial & \multicolumn{2}{c}{ Pacientes } \\
\hline Fluconazol + omeprazol & N & $\%$ \\
Fluconazol + diazepam & 28 & 40,0 \\
Fluconazol + ciclosporina & 13 & 18,5 \\
Fluconazol + dexametasona & 11 & 15,7 \\
Fluconazol + fenitoína & 10 & 14,2 \\
Fluconazol + sertralina & 3 & 4,2 \\
Fluconazol + ciclofosfamida & 2 & 2,8 \\
\hline
\end{tabular}

Quanto as IM que ocorreram com a ciprofloxacina, verificou-se na literatura 8 distintas, todavia, apenas 4 foram identificadas neste grupo de pacientes (Tabela 12)

Tabela 12 - Distribuição dos pacientes submetidos a transplante de medula óssea segundo interações medicamentosas potenciais com a ciprofloxacina. São Paulo, 2005.

\begin{tabular}{llc}
\hline Interação medicamentosa potencial & \multicolumn{2}{c}{ Pacientes } \\
\hline Ciprofloxacina + ciclosporina & N & $\%$ \\
Ciprofloxacina + ciclofosfamida & 1 & 1,4 \\
Ciprofloxacina + dexametasona & 1 & 1,4 \\
Ciprofloxacina + diazepam & 1 & 1,4 \\
Ciprofloxacina + fluconazol & 1 & 1,4 \\
Ciprofloxacina + fentanil & 0 & - \\
Ciprofloxacina + sertralina & 0 & - \\
Ciprofloxacina + teicoplamina & 0 & - \\
\hline
\end{tabular}


Para o sulfametoxazol+trimetoprima foram verificadas 2 interações potenciais, que ocorreram em 4 pacientes (Tabela 13)

Tabela 13 - Distribuição dos pacientes submetidos a transplante de medula óssea segundo interações medicamentosas potenciais com o sulfametoxazol+trimetoprima. São Paulo, 2005.

\begin{tabular}{llc} 
Interação medicamentosa potencial & \multicolumn{2}{c}{ Pacientes } \\
\hline sulfametoxazol + trimetoprima + ciclosporina & N & $\%$ \\
sulfametoxazol + trimetoprima + fenitoína & 2 & 2,9 \\
& 2 & 2,9
\end{tabular}

A IM potencial entre a levofloxacina e a ciclofosfamida, apesar de ser citada na literatura, não ocorreu em nenhum paciente.

Dentre as IM potenciais $(n=13)$ identificadas, observou-se que todas foram do tipo farmacocinética, afetando principalmente o processo de metabolismo dos agentes administrados concomitantemente (84,6\%) (Figura $16)$.

Figura 16-Tipos de interações medicamentosas potenciais e respectivos processos alterados. São Paulo, 2005.

\begin{tabular}{|l|c|c|}
\hline Interação medicamentosa & Tipo de interação & Processo alterado \\
\hline Ciprofloxacina+ciclofosfamida & Farmacocinética & Absorção \\
\hline Ciprofloxacina+ ciclosporina & Farmacocinética & Metabolismo \\
\hline Ciprofloxacina+dexametasona & Farmacocinética & Metabolismo \\
\hline Ciprofloxacina+ diazepam & Farmacocinética & Metabolismo \\
\hline Fluconazol+ciclosporina & Farmacocinética & Metabolismo \\
\hline Fluconazol+ciclofosfamida & Farmacocinética & Metabolismo \\
\hline Fluconazol+dexametasona & Farmacocinética & Metabolismo \\
\hline Fluconazol+diazepam & Farmacocinética & Metabolismo \\
\hline Fluconazol+fenitoína & Farmacocinética & Metabolismo \\
\hline Fluconazol+ sertralina & Farmacocinética & Metabolismo \\
\hline Fluconazol+omeprazol & Farmacocinética & Absorção \\
\hline Sulfametoxazol+trimetopima+ciclosporina & Farmacocinética & Metabolismo \\
\hline Sulfametoxazol +trimetopima +fenitoína & Farmacocinética & Metabolismo \\
\hline
\end{tabular}


Na Figura 17 verifica-se que 77,0\% das IM potencias apresentou como implicação clinica, elevação dos níveis séricos do agente combinado com o antimicrobiano. Observou-se, também, que a maioria $(61,5 \%)$ das IM apresentou tempo de inicio dos efeitos demorado, ou seja, período superior a $72 \mathrm{~h}$ ou até semanas.

Figura 17 - Interações medicamentosas potenciais e respectivas implicações clínicas, evidências cientificas e tempo de inicio dos efeitos. São Paulo, 2005.

\begin{tabular}{|c|c|c|c|}
\hline Interaçãomedicamentosa potencial & Implicação Clínica & $\begin{array}{l}\text { Evidência } \\
\text { cientifica }\end{array}$ & Início \\
\hline Ciprofloxacina+ciclofosfamida & $\downarrow$ do efeito antimicrobiano & Possível & Demorado \\
\hline Ciprofloxacina+ ciclosporina & 个 do nível sérico da ciclosporina & Suspeita & Demorado \\
\hline Ciprofloxacina+dexametasona & $\begin{array}{l}\text { 个 da excreção da dexametason e da } \\
\text { ciprofloxacina }\end{array}$ & $\mathrm{NE}$ & NE \\
\hline Ciprofloxacina+ diazepam & $\uparrow$ do nível sérico do diazepam & Possível & Demorado \\
\hline Fluconazol+ciclosporina & 个 do nível sérico da ciclosporina & Estabelecida & Demorado \\
\hline Fluconazol+ciclofosfamida & $\uparrow$ do nivel sérico da ciclofosfamida & $\mathrm{NE}$ & NE \\
\hline Fluconazol+dexametasona & 个 do nível sérico do corticosteróide & Suspeita & Demorado \\
\hline Fluconazol+diazepam & $\uparrow$ do nível sérico do diazepam & Estabelecida & Rápido \\
\hline Fluconazol+fenitoína & 个 do nível sérico da fenitoína & Provável & Demorado \\
\hline Fluconazol+ sertralina & $\uparrow$ do nível sérico da sertralina & NE & NE \\
\hline Fluconazol+omeprazol & $\downarrow$ da absorção do antifungico & Suspeita & Rápido \\
\hline Sulfonamida+trimetoprima+ciclosporina & $\downarrow$ do nível sérico da ciclosporina & Suspeita & Demorado \\
\hline Sulfonamida +trimetoprima +fenitoína & 个 do nível sérico da fenitoína & Provável & Demorado \\
\hline
\end{tabular}

NE - não especificado 
Observa-se na Figura 18 que as IM com nível de severidade moderado requerem monitoramento da terapia combinada. Todavia, a IM do fluconazol + fenitoína e o fluconazol + omeprazol necessitam modificação da terapia.

Figura 18 - Interações medicamentosas potenciais e respectivos níveis de severidade e risco para terapia combinada. São Paulo, 2005.

\begin{tabular}{|c|c|c|}
\hline Interação medicamentosa potencial & Nível de severidade & $\begin{array}{l}\text { Nível de risco da } \\
\text { terapia combinada }\end{array}$ \\
\hline Ciprofloxacina + ciclofosfamida & Moderada ${ }^{(19)}$ & $\mathrm{C}$ \\
\hline Ciprofloxacina + ciclosporina & Moderada ${ }^{(19)}$ & $\mathrm{C}$ \\
\hline Ciprofloxacina + dexametasona & Moderada ${ }^{(20)}$ & $\mathrm{C}$ \\
\hline Ciprofloxacina + diazepam & Menor ${ }^{(19)}$ & C \\
\hline Fluconazol + ciclosporina & Moderada ${ }^{(19)}$ & $\mathrm{C}$ \\
\hline Fluconazol + ciclofosfamida & Moderada $^{(20)}$ & C \\
\hline Fluconazol + dexametasona & Moderada ${ }^{(19)}$ & $\mathrm{C}$ \\
\hline Fluconazol + diazepam & Moderada $^{(19)}$ & $\mathrm{C}$ \\
\hline Fluconazol + fenitoína & Moderada $^{(19)}$ & $\mathrm{D}$ \\
\hline Fluconazol + sertralina & Moderada $^{(20)}$ & $\mathrm{C}$ \\
\hline Fluconazol + omeprazol & Moderada ${ }^{(19)}$ & $\mathrm{D}$ \\
\hline Sulfametoxazol+trimetoprima + ciclosporina & Moderada ${ }^{(19)}$ & C \\
\hline Sulfametoxazol+trimetoprima +fenitoína & Moderada ${ }^{(19)}$ & C \\
\hline
\end{tabular}

Quanto ao nível de severidade das IM potenciais, observaram-se que $92,3 \% \%$ foram do tipo moderada (Tabela 14 ) 
Tabela 14 - Nível de severidade das interações medicamentosas potenciais dos antimicrobianos São Paulo, 2005.

\begin{tabular}{lcc} 
& Nível de severidade & \multicolumn{2}{c}{ Interações medicamentosas potenciais } \\
& $\mathbf{N}$ & $\%$ \\
\hline Severa & - & - \\
Moderada & 12 & 92,3 \\
Menor & 1 & 7,7 \\
\hline Total & $\mathbf{1 3}$ & $\mathbf{1 0 0 , 0}$ \\
\hline
\end{tabular}

No que diz respeito ao nível de evidência cientifica das IM, verificou-se que a maioria $(61,6 \%)$ apresentou documentação de boa qualidade, derivada de ensaios clínicos $(30,8 \%)$ e de relatos de caso $(30,8 \%)$ (Tabela 15).

Tabela 15 - Nível de evidência cientifica das interações medicamentosas potenciais dos antimicrobianos. São Paulo, 2005.

\begin{tabular}{lcc}
\hline Nível de evidência cientifica & Interações medicamentosas potenciais \\
\hline 1 (Estabelecida) & N & $\%$ \\
2 (Provável) & 2 & 15,4 \\
3 (Suspeita) & 2 & 15,4 \\
4 (Possível) & 4 & 30,8 \\
5 (Improvável) & 2 & 15,4 \\
Não especificada & - & - \\
\hline Total & 3 & 23,0 \\
\hline
\end{tabular}

A Tabela 16 aponta que $77,0 \%$ das IM potenciais apresentaram nível de risco $\mathrm{C}$, ou seja, há que se monitorar o regime terapêutico. 
Tabela 16 - Nível de risco de terapia combinada das interações medicamentosas potenciais dos antimicrobianos. São Paulo, 2005.

\begin{tabular}{lcc}
\hline Nível de risco de terapia combinada & \multicolumn{2}{c}{ Interações medicamentosas potenciais } \\
\hline A & $\mathbf{N}$ & $\%$ \\
B & - & \\
C & 10 & 77,0 \\
D & 2 & 15,4 \\
X & - & 7,6 \\
Não especificada & 1 & $\mathbf{1 0 0 , 0}$ \\
\hline Total & $\mathbf{1 3}$ & \\
\hline
\end{tabular}

Observou-se associação estatisticamente significante entre ocorrência de IM e sexo ( $p<0,001)$, havendo para o masculino uma chance 2,4 vezes a do feminino. Verificou-se também associação estatisticamente significante com faixa etária 40-49 anos $(p<0,001)$. demonstrando que a chance de IM nestes indivíduos foi cerca de 6,2 vezes a daqueles menores de 19 anos. Em relação ao TMO não se observou associação estatisticamente significante. Quanto a variável número de medicamentos identificou-se associação estatisticamente significante $(p<0,001)$. Os pacientes que receberam um número de medicamentos superior a 4 , a chance de IM foi 6.9 a daqueles que receberam numero inferior a este (Tabela 17). 
Tabela 17 - Associação entre interações medicamentosas potenciais e variáveis demográfico-clinicas. São Paulo, 2005.

\begin{tabular}{|c|c|c|c|c|}
\hline \multirow{2}{*}{ Variáveis demográfico-clinicas } & \multirow[t]{2}{*}{ OR } & \multicolumn{2}{|c|}{ Intervalo de confiança $95 \%$} & $\mathbf{P}$ \\
\hline & & LI & LS & \\
\hline
\end{tabular}

\section{Sexo}

Feminino (1)

Masculino

Faixa etária

$<$ ou igual $19(1)$

$20-29$

$30-39$

$40-49$

$>50$

Tipo de transplante

Autólogo (1)

Alogênico

Número de medicamentos

$<$ que 4 (1)

$>$ que 4

$\mathrm{P}<0,05$

Ajustado por sexo e idade

Grupo de referência $=1$
1

$\begin{array}{llll}2,4 & 2,013 & 2,887 & <0,001\end{array}$

1

$\begin{array}{llll}0,977 & 0,634 & 1,506 & 0,917\end{array}$

$\begin{array}{llll}1,541 & 0,993 & 2,392 & 0,054\end{array}$

6,176

4,008

$9,516<0,001$

1,616

1,096

2,382

0,015

\section{1}

$\begin{array}{llll}0,826 & 0,664 & 1,028 & 0,087\end{array}$ 
Discussão 


\section{DISCUSSÃO}

Os achados do presente estudo relativos aos aspectos demográficoclínicos da amostra foram similares a outros existentes na literatura, os quais apontaram que o TMO, especialmente o autológo, aumentou a partir de 2001 para pacientes do sexo masculino com diagnósticos de linfomas. Além disso, os diagnósticos de maior freqüência (linfomas e mielomas) foram, também, nos Estados Unidos, no ano de 2000, as causas mais freqüentes de TMO autólogo ${ }^{(3,53)}$.

Quanto ao perfil de aprazamento dos horários de administração de medicamentos verificou-se que os resultados obtidos foram semelhantes a outro estudo realizado, também, com pacientes onco-hematológicos, quando se observou que $74,4 \%$ das doses administradas concentraram-se em dois horários, às $10 \mathrm{~h}(34,8 \%)$ e às $22 \mathrm{~h}(39,6 \%)^{(38)}$. Esta concentração de vários medicamentos em determinados horários encontra-se, muitas vezes, relacionada a normas da instituição, bem como a hábitos de trabalho da equipe de enfermagem, que não aprazam medicamentos em horários específicos, no intuito de evitar esquecimentos ou interferências na atividade de administrar medicamentos.

Apesar de não ser foco principal do estudo, verificou-se que a média de medicamentos administrados nos horários das $7 \mathrm{~h}(0,23), 13 \mathrm{~h}(0,24)$ e 19 $\mathrm{h}(1,53)$, que correspondem à troca de plantão, e $15 \mathrm{~h}(0,17)$ e $16 \mathrm{~h}(0,24)$ (Tabela 3) que representam período de visita de familiares, foi menor, permitindo inferir que neste estudo, a equipe de enfermagem evitou utilizar determinados horários, repetindo uma prática que ocorre em vários serviços, que visam muito mais a atender as rotinas institucionais do que atender as necessidades dos pacientes ${ }^{(38)}$. Além disso, cabe destacar que 0 aprazamento simultâneo de medicamentos representa um fator de risco para ocorrência de $\mathrm{IM}$, especialmente aquelas que afetam a absorção e distribuição dos agentes terapêuticos ${ }^{(24)}$. 
Deste modo, os pacientes submetidos a TMO foram particularmente susceptíveis a IM, não apenas pelas suas particularidades clinicas, mas, também, pelo perfil da terapia farmacológica adotada, que foi composta por inúmeros medicamentos, muitos, com características potencialmente interativas, que se mostraram implicados em IM importantes, ou seja, que poderiam resultar em conseqüências para o paciente. Todavia, nestes pacientes, do ponto de vista prático, é possível que os efeitos decorrentes das IM possam passar desapercebidos ou serem interpretados como manifestações da doença.

A relação entre o número de medicamentos utilizado pelo paciente e a ocorrência e IM é bem documentada na literatura, e a incidência deste evento parece elevar-se conforme a idade aumenta e piora a condição clinica do paciente.

No presente estudo verificou-se que, para pacientes na faixa etária de 40 - 49 anos, o risco de exposição às IM potenciais foi 6,2 vezes aos daqueles com idade inferior a 19 anos (Figura 17). Este dado foi semelhante ao obtido por outros autores que, também, demonstraram uma associação positiva entre idade e $\mathrm{IM}^{(40,42)}$.

Em relação ao tipo de TMO não se observou associação estatisticamente significante. Porém, a observação empírica tem mostrado que o TMO alogênico parece mais propenso, tendo em vista que o uso da ciclosporina - o único medicamento envolvido em todas as IM com antimicrobianos - ocorre em todos os pacientes.

Houve associação estatisticamente significante entre o número de medicamentos e a ocorrência de IMs, sendo que para os pacientes que receberam um número de medicamentos superior a 4 , o risco de IM foi 6.9 vezes a aqueles que utilizaram menos que 4 (Figura 17). Outros estudos têm mostrado, também, esta associação. 
Em pacientes clínicos, a média de medicamentos prescritos na alta hospitalar foi $6^{(27)}$. Um estudo realizado em hospital universitário, também, com pacientes internados em clinica médica, mostrou que 100\% da amostra que utilizou 10 ou mais medicamentos por dia foi exposta a uma ou mais IM potenciais ${ }^{(34)}$. Em pacientes críticos, a média de medicamentos utilizados foi 14,7 , sendo detectadas IM potenciais em $44,3 \%$ deles ${ }^{(40)}$.

$\mathrm{Na}$ especialidade de oncologia, um estudo, realizado com pacientes portadores de tumores sólidos e hematólogicos, apontou que a amostra recebeu de 1-20 medicamentos devido a complicações decorrentes da terapia e da doença, com uma média de $8{ }^{(39)}$. Outro estudo mostrou que $81,8 \%$ dos pacientes com leucemia mielóide aguda utilizaram na fase préquimioterapia de 6-9 medicamentos, sendo expostos a combinações terapêuticas potencialmente interativas ${ }^{(38)}$. Este achado foi próximo dos resultados obtidos no presente estudo que, também, analisou o número de medicamentos utilizados na fase de condicionamento do TMO (condicionamento quimioterápico), todavia o número máximo de agentes utilizados foi superior (16). De modo geral, os autores verificaram que o número de IM potenciais aumentou de acordo com a quantidade de medicamentos usados $(27,34,36,41,42,54)$.

Considerando que o número de medicamentos prescritos representa um dos fatores mais importantes na precipitação de $\mathrm{IM}$, e que muitos autores observaram associações positivas entre o número de IM potenciais e a quantidade de medicamentos usados, pode-se afirmar que a amostra investigada encontrava-se exposta a $\mathrm{IM}^{(27,34,36,41,42,54)}$. Este risco foi, certamente, ampliado pelo perfil farmacológico dos medicamentos utilizados pela amostra.

Com relação a esse fator, verificou-se que as classes identificadas foram compatíveis com as necessidades terapêuticas dos pacientes, pois os medicamentos introduzidos na fase do condicionamento visaram evitar, reduzir ou aliviar problemas freqüentes como náusea, vômito, dor, sangramentos, mucosite, decorrentes da quimioterapia antineoplásica ${ }^{(12)}$. 
Os antieméticos mais utilizados (ondansetrona, dimenidrinato e metoclopramida) são considerados essenciais e administrados em altas doses para a prevenção e alívio das náuseas e vômitos. A classe dos analgésicos, a despeito da baixa freqüência, é importante no controle da dor relacionada a mucosite e no controle da febre, comumente associada a neutropenia ou febres tumorais. Além disso, quando o paciente não sente dor, apresenta melhor aceitação alimentar e maior tolerância aos medicamentos administrados por via oral.

A ampla utilização da classe terapêutica dos quimioterápicos justifica-se pela necessidade de prevenir e tratar infecções virais, bacterianas, fúngicas e helmínticas freqüentes nos pacientes submetidos ao TMO. Os antimicrobianos que apresentaram maior freqüência foram aqueles recomendados por especialistas, por exemplo, de acordo com o protocolo do Centers for Desease Control and Prevention ${ }^{(25)}$. Deste modo, o aciclovir utilizado por todos os pacientes (100\%) (Tabela 4) é o antiviral de primeira escolha para a profilaxia de infecções oportunistas (vírus do herpes simples e varicela-zoster) típicas da fase de condicionamento do TMO ${ }^{(56-58)}$.

A antibioticoterapia com agentes de amplo espectro como cefepima e meropenem ocorreu em alguns pacientes, e nestes casos para evitar infecções, relacionadas ao uso de cateter venoso central de longa permanência, causadas principalmente pelo Staphylococcus epidermidis, um agente responsável por infecções fatais ${ }^{(4,59,60)}$.

Destaca-se que os pacientes de TMO também apresentam alto risco para infecções disseminadas por fungos, sendo freqüente a ocorrência de infecções sistêmicas. Este tipo de infecção é uma das principais causas de mortalidade entre os pacientes imunocomprometidos, principalmente aqueles submetidos a TMO, e está relacionada a fatores como tempo prolongado de pancitopenia, uso de antibióticos de amplo espectro, acesso venoso central, quimioterapia, radioterapia e protocolos que utilizam imunossupressão para prevenção de doença do enxerto versus hospedeiro. 
$\mathrm{Na}$ clínica, as infecções fúngicas são causadas principalmente por Cândida spp e Aspergillus spp. ${ }^{(61)}$.Para estes casos, o fluconazol tem mostrado uma atividade significativa na prevenção e tratamento das infecções, além de ser o antifúngico de escolha para os pacientes de TMO e o único utilizado no presente estudo ${ }^{(62)}$. Um estudo que investigou candidemia relacionada ao cateter central, em pacientes submetidos a TMO alogênico, mostrou que muitos fungos foram suscetíveis ao fluconazol ${ }^{(63)}$.

A despeito das indicações clínicas serem adequadas, e plenamente justificadas pelas necessidades dos pacientes, parte expressiva dos medicamentos $(72,7 \%)$ apresentou características potencialmente interativas (Tabela 5), fator que predispunha a ocorrência de IM, e que poderiam comprometer o sucesso terapêutico, dependendo da combinação de medicamentos adotada no regime.

Entre os medicamentos com potencial interativo, a maioria $(79,2 \%)$ foi classificada como precipitador (Tabela 6), ou seja, agentes que atuam, principalmente através dos processos de inibição e indução enzimática, podendo afetar as respostas farmacológicas dos medicamentos objeto $(19,20,22)$. Dentre os precipitadores houve destaque para os inibidores enzimáticos (46,0\%) (Tabela 7).

Quando foram analisados os quimioterápicos antimicrobianos, também, verificou-se que $66,7 \%$ deles eram potencialmente interativos (Tabela 8) e, com exceção da vancomicina e teicoplamina, todos os outros eram inibidores enzimáticos (Tabela 9), podendo causar inibição do metabolismo de um agente objeto, elevando o nível sérico deste, freqüentemente, resultando em aumento da toxicidade ${ }^{(19,20,22)}$.

Deste modo, a análise das IM desta classe terapêutica incluiu o fluconazol, a ciprofloxacina, o levofloxacina e o sulfametoxazol+trimetoprima, uma vez que a vancomicina e a teicoplamina, apesar de serem potencialmente interativas, não apresentaram combinações que poderiam resultar em IM. 
Metade dos pacientes $(n=35)$ foi exposta a combinações que poderiam incidir em IM potencias, independente do antimicrobiano envolvido, sendo que 93,7\% desta amostra apresentou IM potencial decorrente da terapia com o fluconazol. Este antimicrobiano combinou-se com até 5 agentes que apresentaram, também, potencial interativo, porém apenas um paciente foi exposto a esta situação. A combinação com 2 agentes ocorreu em $45,7 \%$ dos pacientes que receberam o antifúngico (Tabela 10).

Para o fluconazol foram identificadas 7 IM potencias, todas do tipo farmacocinético, ou seja, que poderiam afetar o padrão de absorção (fluconazol+omeprazol, fluconazol+ciclofosfamida) ou de metabolização (todas as outras) do agente objeto. Este resultado pode ser justificado pelo fato do fluconazol ser um inibidor enzimático $\left(\mathrm{CYP}_{450}\right)$ das isoenzimas CYP2C8/9, CYP2C19 e CYP3A4 responsáveis pela biotransformação de inúmeros medicamentos ${ }^{(19,20,23)}$.

Quando foram analisadas as IM do ponto de vista de implicação clinica, verificou-se que a maioria delas acarretariam em aumento dos níveis séricos do medicamento combinado ao fluconazol (Figura 17), e 28,5\% necessitariam de uma avaliação cautelosa dos benefícios do uso concomitante e implementação de ações específicas para minimizar os efeitos tóxicos (fluconazol+omeprazol, fluconazol+fenitoína), além de que o médico deveria considerar escolha de agentes alternativos (Tabela 11) ${ }^{(20)}$.

O aumento dos níveis séricos do medicamento objeto, dependendo do agente envolvido, pode apresentar diferentes implicações do ponto de vista clinico. A co-administração de fluconazol e ciclosporina pode aumentar as respostas farmacológicas e a toxicidade do imunossupressor devido à elevação do seu nível sérico ${ }^{(19,20,64)}$. Na clínica esta toxicidade pode ser observada através da alteração da função renal, colestase ou parestesias ${ }^{(64)}$. A ciclosporina é substrato da isoenzima CYP3A4 e o fluconazol inibidor ${ }^{(20)}$, deste modo, pode-se inferir que, apesar dos efeitos de toxicidade não terem sido monitorados, dentre os pacientes submetidos ao TMO alogênico $(n=24)$ quase a metade $(45,8 \%)$ foi exposto a esta IM. 
Sabendo-se que a ciclosporina é um medicamento objeto, cuja alteração no seu nível sérico, por menor que seja, acarreta grandes modificações nos efeitos, a combinação com outros antimicrobianos precipitadores como ciprofloxacina e sulfametoxazol+trimetoprima, também, amplamente utilizados em TMO podem resultar em outras IM potenciais.

As IM da ciprofloxacina com outros medicamentos como ciclosporina, corticosteróides, diazepam, entre outros foram bem descritas na literatura ${ }^{(19,20,64,65)}$. Há descrição de que o regime combinado de ciprofloxacina e ciclosporina em pacientes com aplasia de medula óssea aumentou o nível sérico do imunossupressor ${ }^{(66)}$. Estudo realizado com pacientes submetidos a transplante renal concluiu que no grupo tratado com ciprofloxacina a taxa de rejeição foi superior ao controle, sugerindo que ocorreu uma IM do tipo farmacodinâmica, com antagonismo dos efeitos da ciclosporina $^{(67)}$. Apesar desses resultados, a literatura de modo geral, conclui que a terapia combinada entre os dois agentes terapêuticos pode ser segura desde que haja ajuste posológico e monitoramento dos efeitos e controle dos níveis séricos do imunossupressor ${ }^{(19,20,64,66,68)}$.

$\mathrm{Na}$ prática diária os pacientes submetidos a TMO utilizam o sulfametoxazol + trimetoprima desde o início do condicionamento como profilaxia de Pneumocistis carinii, sendo a terapia interrompida no dia -1 (dia que antecede a infusão da medula óssea). Porém, a ciclosporina é introduzida, também, no dia -1, situação que certamente, predispõe a ocorrência de IM entre esses agentes. Esta IM do tipo farmacocinética afeta o metabolismo e pode resultar em aumento de nefrotoxicidade e redução dos níveis séricos da ciclosporina, elevando o risco de rejeição do enxerto $^{(19,64)}$. O processo de inibição enzimática desencadeado pelo sulfametoxazol + trimetoprima é lento, e mesmo com a sua suspensão no dia -1 , os efeitos decorrentes desta IM devem ser monitorados com cautela, principalmente naqueles pacientes com fatores de risco para nefrotoxicidade. $\mathrm{Na}$ prática, faz-se necessário estabelecer o ajuste 
posológico de acordo com os níveis séricos da ciclosporina para garantir sucesso terapêutico, quando houver regime combinado ${ }^{(20,64,69,70)}$.

Outro medicamento envolvido nas IM com dois antimicrobianos (fluconazol e com o sulfametoxazol+trimetoprima) foi a fenitoína. No contexto do TMO, este anticonvulsivante é utilizado na prevenção da neurotoxicidade causada pelo bussulfano - um quimioterápico antineoplásico prescrito geralmente por quatro dias na fase de condicionamento do TMO. As IM existentes entre esses antimicrobianos e o anticonvulsivante apresentam respostas complexas, uma vez que ambos são capazes de afetar o sistema enzimático, inibindo (antimicrobianos) ou induzindo (fenitoina). Há que se destacar que além de ser a fenitoína um potente indutor enzimático da família de isoenzimas CYP2, ela apresenta alta ligação a PP (>90\%), que são características farmacocinéticas importantes que favorecem IM não apenas com medicamentos mas, também, com alimentos e fitoterápicos ${ }^{(19,20,64,71)}$.

As IM deste anticonvulsivante com o fluconazol ou com 0 sulfametoxazol+trimetoprima apresentam evidência cientifica provável, ou seja, os efeitos adversos decorrentes da interação apresentam alta probabilidade de ocorrência, mas a literatura não dispõe de ensaios clínicos randomizados (19). Todavia há que se considerar que para pacientes gravemente enfermos e submetidos a polifarmácia por longo período, como os investigados no presente estudo, apesar da evidência ser provável, o fenômeno da IM assume grande importância, podendo resultar inclusive em eventos fatais. Um estudo mostrou que $4 \%$ de mortes de pacientes com problemas relacionados ao câncer foram associadas as $\mathrm{IM}^{(72)}$.

No caso especifico da IM entre fluconazol e fenitoína, Bachmann ${ }^{(20)}$ sugere modificação da terapia, devido ao risco de neurotoxicidade manifesto pela ocorrência de hiperreflexia, ataxia, nistagmo e tremores ${ }^{(64)} \mathrm{Na}$ clinica de TMO observa-se empiricamente que alguns pacientes que utilizam esta combinação apresentam crises convulsivas, as quais são associadas ao bussulfano, nem sequer discutindo que este efeito possa ser decorrente de 
IM. Do ponto de vista prático, nas situações em que há necessidade do regime combinado, o clinico deve realizar uma avaliação cautelosa dos benefícios do uso concomitante e implementar ações específicas para minimizar os efeitos tóxicos ${ }^{(20)}$.

No que se refere ao tempo de início das interações, observou-se que foi predominantemente demorado (61,5\%) (Figura 17), um motivo adicional para monitorar 0 paciente durante todo 0 período de acompanhamento (hospitalar e ambulatorial). É importante discutir, ainda, que embora alguns medicamentos utilizados no início do condicionamento medular sejam suspensos para a introdução de outros, os mecanismos farmacológicos que envolvem as IM são demorados, podendo levar de dias a semanas, de modo que, as RAMs podem permanecer ocultas na fase prétransplante, mas estão sujeitas a aparecer no período pós. Tal fato, pode colocar em risco o sucesso da terapia quando se observa que o número de medicamentos na fase de neutropenia é ainda maior, ampliando o risco de IM, principalmente quando se utilizam inibidores enzimáticos.

A maioria das IM (61,6\%) (Tabela 15) verificada entre os antimicrobianos apresentou evidência cientifica de boa qualidade. O Drug Interaction Facts ${ }^{(19)}$, quando comparado a outros programas de rastreamento de IM, foi considerado de maior acurácia, com sensibilidade de especificidade de $97 \%{ }^{(73)}$. Este autor é, ainda, uma das principais fontes de informações sobre IM, por isso sendo amplamente usado em muitos outros estudos $^{(39,74,75)}$.

A despeito da importância de se utilizar um material fidedigno para rastrear as IM, é fundamental que o profissional envolvido no cuidado saiba quais são as estratégias recomendadas na literatura.

Alguns autores apontaram o uso de prescrições médicas eletrônicas com alertas para identificação de IM potenciais ${ }^{(54,76,77)}$; participação do farmacêutico ${ }^{(39,76)}$; o monitoramento do número de agentes prescritos; a realização de ajuste posológico baseado nos níveis séricos dos 
medicamentos e modificação da terapia, quando possível; e a implementação do uso racional de medicamentos ${ }^{(45,47,49,78)}$.

Outros estudos recomendam o uso de algoritmo unificado para o diagnóstico das RAMs relacionadas à IM e a utilização de guidelines nos serviços ${ }^{(79-82) .}$

Estratégias que têm contribuído bastante para a prevenção e manejo de IM são : a utilização de tabelas contendo as principais IM potenciais nas unidades de internação; a disponibilização de banco de dados on line sobre IM, com fácil acesso aos profissionais envolvidos no processo de administração de medicamentos ${ }^{(35,41,83)}$; e o monitoramento de pacientes submetidos a polifarmácia e aqueles que apresentam outros fatores de risco para a ocorrência de $\mathrm{IM}^{(44,84)}$.

Quando se tratar de novos medicamentos, a investigação de possíveis IM pode ser feita através de estudos in vitro e in vivo sobre a farmacocinética e farmacodinâmica dos medicamentos ${ }^{(84-87)}$.

A equipe de enfermagem além de poder envolver-se em várias das medidas apontadas, apresenta um papel fundamental na prevenção de IM por meio da realização de aprazamento de horários de medicamentos planejado, observando os agentes que podem ser combinadas, a seqüência e a via da administração ${ }^{(24,27)}$. 
Conclusões 


\section{CONCLUSÕES}

O presente estudo possibilitou extrair as seguintes conclusões:

- a classe terapêutica dos quimioterápicos antiomicrobianos $(34,0 \%)$ foi a mais utilizada pelos pacientes na fase de condicionamento do TMO, havendo destaque para os antimicrobianos aciclovir (100\%), cefepima $(47,1 \%)$ e fluconazol $(45,7 \%)$;

- a maioria dos medicamentos (72,7\%) apresentou potencial interativo, sendo que $79,2 \%$ eram precipitadores das IM e, principalmente, com capacidade de afetar o metabolismo hepático $(66,8 \%)$;

- dentre os quimioterápicos antimicrobianos $66,7 \%$ possuíam potencial interativo, e $66,6 \%$ eram inibidores enzimáticos;

- metade dos pacientes foi exposta a combinações de antimicrobianos potencialmente interativos e outros medicamentos;

- os antimicrobianos potencialmente interativos envolvidos em IM foram fluconazol, ciprofloxacina e sulfametoxazol+trimetoprima;

- foram identificadas 13 IM distintas;

- o fluconazol foi responsável por $85,7 \%$ das IM identificadas a partir das combinações, dando origem a sete IM potenciais, cuja maioria dos pacientes $(40,0 \%)$ utilizou fluconazol+omeprazol;

- a ciclosporina e a fenitoína foram envolvidas nas IM potencias do fluconazol e ciprofloxacina; 
- todas as IM existentes entre antimicrobianos e outros medicamentos foram do tipo farmacocinética, afetando principalmente o processo de metabolização $(84,6 \%)$;

- a maioria das IM (92,3\%) apresentou severidade moderada, com bom nível de evidência cientifica $(61,6 \%)$, que poderiam resultar em elevação dos níveis séricos do agente combinado com 0 antimicrobiano $(77,0 \%)$, com tempo de inicio dos efeitos demorado $(61,5 \%)$, cujo risco da terapia combinada implica em monitorar os níveis séricos e toxicidade dos agentes envolvidos $(76,9 \%)$;

- Houve associação estatisticamente significante entre ocorrência de IM e sexo $(p<0,001)$; entre IM e faixa etária 40-49 anos $(p<0,001)$ e naqueles indivíduos com idade igual ou maior que 50 anos $(p<0,015)$; entre IM e número de medicamentos maior que $4(p<0,001)$. 
Considerações Finais 


\section{CONSIDERAÇÕES FINAIS}

Apesar dos pacientes submetidos a TMO serem bastante controlados do ponto de vista clínico e laboratorial, o que faz com que se acredite que as IM não afetem de modo importante à evolução clinica do paciente, é de suma importância reconhecer este evento como um problema comum da prática, que pode resultar em efeitos potencialmente perigosos e, por isso, deve ser evitado. Além disso, a repercussão clinica pode não ser observada facilmente, deste modo, a relação causa e efeito pode não ser estabelecida, especialmente nestes pacientes clinicamente debilitados.

No que diz respeito à obtenção de informações acerca das IM, verifica-se no âmbito dos serviços que as mesmas nem sempre são de fácil acesso e completas, tendo em vista que para muitos locais o único meio disponível é o Dicionário de Especialidades Farmacêuticas - DEF. Este material, além de não contemplar a maioria dos medicamentos disponíveis no mercado, disponibiliza informações que constam da bula do produto, ou seja, fornecida pelo fabricante. Além disso, muitas fontes são disponíveis na língua inglesa (periódicos, compêndios, base de dados on-line). Este fato, de certo modo, limita o acesso de muitos profissionais diretamente envolvidos com o cuidado de saúde, tendo em vista que os livros são caros e ficam restritos a instituições de ensino e pesquisa e, alguns, serviços privados. Outro problema é que, muitas vezes, há disponibilidade de acesso às bases de dados, todavia os usuários não são treinados para utilizarem este recurso.

Deste modo, os profissionais envolvidos no cuidado aos pacientes submetidos a TMO, ainda, que conheçam as IM que apresentam importância clinica, devem estar alerta para detectá-las e atuar nas conseqüências.

Finalmente cada apontar as contribuições e limitações do presente estudo. 
$\mathrm{Na}$ especialidade de TMO, o presente estudo é pioneiro na investigação do tema IM, trazendo além de informações acerca das IM, 0 nível de risco da terapia combinada, variável que pode subsidiar a prática clinica - não apenas da equipe de enfermagem, mas principalmente, da equipe médica.

A identificação das IM foi realizada utilizando-se o Drug Interaction Facts, uma referência mundialmente adotada em vários estudos sobre o tema, o que possibilitará comparações com trabalhos futuros.

Os resultados obtidos fornecem subsídios para proposição de intervenções de enfermagem relacionadas aos medicamentos potencialmente interativos, bem como para as IM dos antimicrobianos analisados.

Apesar das contribuições, existem limitações que merecem serem apontadas para que estudos posteriores venham a saná-las. A realização da coleta de dados de um único dia (-1 da fase do condicionamento) excluiu a possibilidade de identificação de outras possíveis IM, uma vez que, na fase pós-transplante a polifarmácia é mais complexa ainda. Além disso, não foram analisadas as IM com alimentos e, a despeito da maioria dos medicamentos (66,7\%) ser administrada por via intravenosa, a questão da incompatibilidade não foi investigada - elemento que certamente forneceria material para um outro estudo.

A análise das IM incluiu apenas os antimicrobianos potencialmente interativos não contemplando a totalidade das IM existentes entre outros agentes, independente das características farmacológicas. 
Referências 


\section{REFERÊNCIAS}

1. Thomas ED, Blume KG, Forman SJ. Hematopoietic cell transplantation. Oxford: Blackwell Science; 2000.

2. Wingard JR, Volgelsang GB, Deeg HJ. Stem cell transplantation: supportive care and long-term complications. Hematology Am Soc Hematol Educ Program [serial online]. 2002;:422-44. Available from: www.asheducationbook.org/cgi/conten [Acesso em 9 fev. 2004].

3. Horowitz MM. Report on state of the art in blood and marrow transplantation. The IBMTR/ABMTR Summary slides with guide. IBMTR/ABMTR Newsletter [serial online]. 2002; 9(1). Available from: em:www.cibmtr.org/ABOUT/NEWS/2002Feb.pdf [Acesso em 20 jun. 2005].

4. Dulley FL. Transplante de medula óssea: informações na área da hematologia e hemoterapia. In: Hemonline [online]. Salvador; 1997. Disponível em: <http://www.hemonline.com.br >. [Acesso em 14 set. 2000].

5. Registro Brasileiro de Transplantes. São Paulo: Associação Brasileira de Transplantes de Órgãos (ABTO). 2000;6(4):20.

6. Mc Cullough J, Hansen J, Perkins $\mathrm{H}$. The national marrow Donor program: how it works, accomplishments to date. Oncology. 1972; 31A:163-8.

7. Barros JC. Transplante de celulas hematopeticas. In: Guimarães JRQ. Manual de oncologia. $2^{\mathrm{a}}$ ed. São Paulo: BBS; 2006. Cap.13, p.219-35.

8. Mc Leod HL. Clinically relevant drug-drug interactions in oncology. $\mathrm{Br} \mathrm{J}$ Clin Pharmacol. 1998; 45(6):539-44.

9. Dulley FL. Complicações precoces no tratamento de transplante medula óssea alogênico: análise de 44 pacientes [tese]. São Paulo (SP): Faculdade de Medicina da USP; 1992. 
10. Ralph JOW, Albert DB. Bone marrow disfunction in the cancer pacient. In: Vincent DT, Samuel H, Steven RA. Cancer principles \& practice of oncology. $4^{\text {th }}$ ed. Philadelphia: J. B. Lippincott; 1993.

11. Sullivan KM, Dykewicz CA, Longworth DL, Boeckh M, Baden LR, Rubin $\mathrm{RH}$, et al. Preventing opportunistic infections after hematopoietic stem cell transplantation: the Center for Disease Control and Prevention, Infectious Diseases Society of America, and American Society for Blood and Marrow Transplantation Practice Guidelines and beyond. Hematology Am Soc Hematol Educ Program [serial online]. 2001:392. Available from: www.asheducationbook.org/cgi/conten. [Acesso em 9 fev. 2004].

12. Eldar R. Quality of patient care in bone marrow transplantation. Croat Med J. 2004;45(6):786-8.

13. O'Brien SN, Blijlevens NMA, Mahfouz TH, Anaissie EJ. Infections in patients with hematological cancer: recent developments. Hematology (Am Soc Hematol. Educ Prog) [serial online] 2003: 438-72. Available from: http://www.asheducationbook.org/cgi/. [Acesso em 9 fev 2004].

14. Saboya R. Infecções bacterianas e fúngicas no transplante de medula óssea: análise de 186 pacientes [tese]. São Paulo (SP): Faculdade de Medicina da USP; 1998.

15. Rocha IFD. Infecção no local da saída e túnel subcutâneo de cateteres tipo Hickman em pacientes de TMO alogênico, relacionado aos antisépticos a base de polivinilpirrolidona-iodo e gluconato de clorohexidina [dissertação]. São Paulo (SP): Escola de Enfermagem da USP; 2000.

16. Ninin E, Mipied N, Moreau P, André-Richet B, Morineau N, Mahé B, et al. Longitudinal study of bacterial, viral, and fungal infections in adult recipients of bone marrow transplants. Clin Infect Dis. 2001;33 (1):41-7.

17. Macedo MCMA. Doença enxerto contra hospedeiro aguda e crônica no transplante de medula óssea: análise de 167 pacientes [tese]. São Paulo (SP): Faculdade de Medicina da USP; 1998. 
18. Tirkkonen TM, Laine KMD. Drug interactions with the potencial to prevent prodrug activation as a commom source of irrational prescribing in hospital inpatients. Clin Pharmacol Ther. 2004;76(6):639-47.

19. Trato DS. Drug interactions facts. Saint Louis: Facts and Comparisons; 2002.

20. Bachmann KA. Drug interactions handbook. Huson: Lexi; 2003.

21. Hansten PD, Horn JR. Hansten and Horn's drug interactions analysis and management. Vancouver: Applied Therapeutics; 1999.

22. Grahame-Smith DG, Aronson JK. Interações medicamentosas. In: Grahame-Smith DG, Aronson JK. Tratado de farmacologia clínica e farmacoterapia. Rio de Janeiro: Guanabara Koogan 2004. p. 98-109.

23. Oga S, Basile AC, Carvalho MF. Guia Zanini-Oga de interações medicamentosas. São Paulo: Atheneu; 2002.

24. Secoli SR. Interações medicamentosas: fundamentos para a prática clínica da enfermagem. Rev Esc Enferm USP. 2001;35(1):20-6.

25. Andersson TB, Bredberg $E$, Ericsson $H$, Sjoberg $H$. An evaluation of the in vitro metabolism data for predicting the clearance and drug-drug interaction potential of CYP2C9 substrates. Drug Metab Dispos. 2004;32(7):715-21.

26. Agência Nacional de Vigilância Sanitária (ANVISA). Informe SNVS/ ANVISA/ UFARM [periódico online]. 2001;(6) Disponível em: http://www.anvisa.gov.br/farmacovigilancia/informes/2001/informe 6.ht $\underline{\mathrm{m}}$ [Acesso em 9 mar 2006].

27. Egger SS, Jurgen Drewe, Raymond G. Schlienger. Potential drug-drug interactions in the medication of medical patients at hospital discharge. Eur J Clin Pharmacol. 2004;58(11):773-8.

28. Gosney M, Tallis R. Prescription of contraindicated and interacting drugs in elderly patients admitted to hospital. Lancet. 1984; 2 (8402):564-7. 
29. Mitchell GW, Stanaszek WF, Nichols NB. Documenting drug-drug interactions in ambulatory patients. Am J Hosp Pharm. 1979; 36(5):6537.

30. Schneider JK, Mion LC, Frengley JD. Adverse drug reactions in an elderly outpatient population. Am J Hosp Pharm. 1992; 49(1):90-6.

31. Manchon ND, Bercoff E, Lemarchand P, Chassagne P, Senant J, Bourreille $J$. Fréquence et gravité des interactions médicamenteuses dans une population agée: etude prospective concernant 639 malades. Rev Med Interne. 1989; 10(6):521-25.

32. Shinn AF, Shrewsbury RP, Anderson KW. Development of a computerized drug interaction database (MEDICOM) for use in a patient specific environment. Drug Inf J. 1983;17(3):205-10.

33. Bjorkman IK, Fastbom J, Schmidt IK, Bernsten CB. Drug-drug interactions in the elderly. Ann Pharmacothe. 2002; 36(11):1675-81.

34. Sehn R et al. Interações medicamentosas potenciais em prescrições de pacientes hospitalizados. Infarma. 2003;15:77-81.

35. Madrid JLV. Riesgo de interacciones medicamentosas: combinaciones de medicamentos associados a arritmia ventricular. Rev Invest Clin. 2002; 54 (3):192-7.

36. Carter BL, Lund BC, Hayase N, Chrischilles E. A longitudinal analysis of antihypertensive drug interactions in a Medicaid population. Am J Hypertens. 2004; 17 (5 Pt 1):421-7.

37. Miyasaka LS, Atallah NA. Risco de interação de drogas: combinações de uso de antidepressivos e outras drogas. Rev Saúde Pública. 2003;37(2):203-11.

38. Secoli SR, Padilha KG. Polifarmácia em leucemia mielóide aguda: administração e interação de medicamentos. Prática Hosp. 2005;7(17):78-85. 
39. Riechelmnn RP, Moreira F, Smaletz O, Saad ED. Potential for drug interactions in hospitalized patients. Cancer Chemother Pharmacol. 2005; 56(3):286-90.

40. Sierra P, Castillo J, Gomez M, Sorribes V, Monterde J, Castano J. Interacciones farmacológicas potenciales y reales em pacientes en estado crítico. Rev Esp Anestesiol Reanim. 1997;44(10):383-7.

41. Gaeta TJ, Fiorini M, Ender K, Bove J. Potential drug-drug interactions in elderly patients presenting with syncope. J Emerg Med. 2002; 22(2):159-62.

42. Calvet A, Diez de Ulzurrun M, Perez MT, Esteras J. Interacciones farmacológicas en tratamientos crónicos: medidas correctoras para su prevención en un área básica de salud rural. Aten Primaria. 2001; 27(1):33-7.

43. Oliveira RC, Camargo AEB, Cassiani SHDB. Estratégias para prevenção de erros de medicação no setor de emergência. Rev Bras Enferm. 2005;58(4):399-404.

44. Sucar DD, Sougey EB, Cantilino A, Marinho R. Interações medicamentosas dos antidepressivos noradrenérgicos/ serotoninérgicos. J Bras Psiquiatr. 2003; 52 (2):137-42.

45. Gallagher LP. The potential for adverse drug reaction in elderly patients. Appl Nurs Res. 2001; 14 (4):220-4.

46. Gorzoni ML. Aspectos da farmacologia clínica em pacientes idosos. Gerontologia. 1993;1 (11): 9- 12.

47. Delafuente JC. Undersdending and preventing drug interactions in elderly patients. Crit Rev Oncol Hematol. 2003;48 (2):133-43.

48. Anderson JR, Nawarskas JJ. Cardiovascular drug-drug interactions. Cardiol Clin. 2001;19(2):215-34. 
49. Ledwidge $M$, Travers $B$, Ryder $M$. Specialist care of heart failure improves appropriate pharmacotherapy at the expense of greater polypharmacy an drug-drug interactions. Eur J Heart Fail. 2004;6 (2):235-43.

50. Polit DF, Beck CT, Hungler BP. Fundamentos de pesquisa em enfermagem. 5a ed. Porto Alegre: Artmed; 2004.

51. Zanini AC, Basile AC, Follador W, Oga Seize. Guia de medicamentos. $2^{\underline{a}}$ ed. São Roque, SP: IPEX Editora; 1997.

52. MICROMEDEX® Healthcare Series [online]. Available from: www.periodicos.capes.gov.br. [Acesso em 5.set.2005].

53. Johnson PW, Orchard K. Bone marrow transplants: new indications explit the immune effects of the transplanted cells. BMJ. 2002; 325(7360):348-9.

54. Carter BL, Lund BC, Hayase N, Chrischilles E. The extent of potential antihypertensive drug interactions in a medicaid population. Am J Hypertens. 2002; 15(11):953-7.

55. Centers for Disease Control and Prevention; Infectious Disease Society of America, American Society of Blood and Marrow Transplantation. Guidelines for preventing opportunistic infections among hematopoietic stem cell transplant recipients. MMWR 2000; 49(RR-10):1-125.

56. Naoum FA, Martins LTV, Castro NS, Barros JC, Chiattone CS. Perfil microbiológico dos pacientes nos primeiros trinta dias pós-transplante de medula óssea do Serviço de Transplantes da Santa Casa de São Paulo. Rev Bras Hematol Hemoter. 2002; 24(2): 91-6.

57. Oh SJ, Lee KH, Lee JH, Choi SJ, Kim WK, Lee JS, et al. The risk of cytomegalovirus infection in non-myeloablative peripheral stem cell transplantation compared with conventional bone marrow transplantation. J Korean Med Sci. 2004;19(2):172-6.

58. Danve-Szatanek C, Aymard M, Thouvenot D, Morfin F, Agius G, Bertin $I$, et al. Surveillance network for herpes simplex virus resistence to antiviral drugs: 3-year follow-up. J Clin Microbiol. 2004; 42(1):242-9. 
59. Gales AC, Jones RN, Andrade SS, Sader HS. Antimicrobial susceptibility patterns of unusual nonfermentative gram-negative bacilli isolated from Latin America: report from the SENTRY Antimicobial Surveillance Program (1997-2002). Mem Inst Oswaldo Cruz. 2005;100(6):671-7.

60. Vincent AL, Price R, Field T, Greene JN, Sandin RL, et al. Addition of fluoroquinilone prophylaxis to a blood and marrow transplant unit to reduce gram-negative infections. Cancer Control. 2005;12(3):203-6.

61. Oliveira JSR, Kerbauy FR, Colombo AL, Bahia DMM, Pinheiro GS, Silva $M R R$, et al. Fungal infections in marrow transplant recipients under antifungal prophylaxis with fluconazole. Braz J Med Biol Res. 2002; 35(7): 789-98.

62. Hiemenz J, Cagnoni P, Simpson D, Devine S, Chao N, Keirns J, et al. Pharmacokinetic and maximum tolerated dose study of Micafingin in combination with Fluconazole versus Fluconazole alone for prophylaxis of fungal infections in adult patients undergoing a bone marrow or peripheral stem cell transplant. Antimicrob Agents Chemother. 2005;49(4):1331-6.

63. D'Antonio D, Romano F, Pontieri E, Fioritoni G, Caracciolo C, Bianchini $S$, et al. Catheter- related candidemia caused by candida lipolytica in a patient receiving allogeneic bone marrow transplantation. J Clin Microbiol. 2002; 40 (4):1381-6.

64. MICROMEDEX® Healthcare Series [online]. Available from: www.periodicos.capes.gov.br. [Acesso em 20.jul.2006].

65. Stein GE. Drug interactions with fluoroquinilones. Am J Med. 1991; $91(6 A)$ 81S-86S.

66. Borras-Blasco J, Conesa-Garcia V, Navarro-Ruiz A, Marin-Jimenez F, Gonzales-Delgado M, Gomes- Corrons A. Ciprofloxacin, but not levofloxacin, affests cyclosporine levels in a patient with pure red blood cell aplasia. Am J Med Sci. 2005;330(3):144-6. 
67. Wrishko RE, Levine M, Primmett DR, Kim S, Partovi N, Lewis S, et al. Investigation of a possible interaction between ciprofloxacin and cyclosporine in renal transplant patients. Transplantation. 1997; 64(7): 996-9.

68. Hoey LL, Lake KD. Does ciprofloxacin interact with cyclosporine?. Ann Pharmacother. 1994;28(1):93-6

69. Kagawa Y, Sawada J, Yamada S, Matsuda H, Kageyama S, Masuya $\mathrm{MB}$, et al. Relationship between development of nephrotoxicity and blood concentration of cyclosporine $A$ in bone-marrow transplanted recipients Who received the continuous infusion. Biol Pharm Bull. 2003; 26(8):1115-9.

70. Bartynski WS, Zeigler ZR, Shadduck RK Lister J. Pretransplantation conditioning influence on the occurrence of cyclosporine or FK-506 neurotoxicity in allogeneic bone marrow transplantation. AJNR Am J Neuroradiol. 2004;25 (2):261-9.

71. Lai CM, Moore P, Quon CY. Binding of fosphenytoin, phosphate ester pro drug of phenytoin, to human serum proteins and competitive binding with carbamazepine, diazepam, phenobarbital, phenylbutazone, phenytoin, valproic acid, or warfarin. Res Commun Mol Pathol Pharmacol. 1995; 88(1):51-62.

72. Bjerrum L, Anderson M, Petreson Gm Kragstrup J. Exposure to potential drug interactions in primary health care. Scand J Prim Health Care. 2003; 21(3):153-8.

73. Barrons R. Evaluation of personal digital assistant software for drug interactions. Am J Health Syst Pharm. 2004; 61(4):380-5.

74. Beers $\mathrm{MH}$, Storrie $\mathrm{M}$, Lee $\mathrm{G}$. Potential adverse drug interactions in the emergency room. An issue in the quality of care. Ann Intern med. 1990; 112: 61-64. 
75. Goldberg RM, Mabee J, Mammone M, Chan L, Tarleton G, Broderick S, Robinson DC et al. A comparison of drug interaction software programs: applicability to the emergency department. Ann Emerg Med. 1994; 24: 619-625.

76. Sheldon H, Preskorn, MD. Haw drug-drug interactions can impact managed care. Am J Manag Care. 2004; 10(6 Suppl):S186-98.

77. Glassman PA, Simon B, Belperio P, Lanto A. Improving recognition of drug interactions: benefits and barriers to using automated drug alerts. Med Care. 2002; 40(12):1161-71.

78. Yang J, Kjellsson M, Rostami-Hodjegan A, Tucker G. The effects of dose staggering on metabolic drug-drug interactions. Eur J Pharm Sci. 2003; 20(2):223-32.

79. Wongpoowarak W, Wongpoowarak P. Unified algorithm for real-time detection of drug interaction and drug allergy. Comput Methods Programs Biomed. 2002; 68(1):63-72.

80. Spradling P, Drociuk D, Mclaughlin S. Drug-drug interactions in inmates treated for human immunodeficiency virus and mycobacterium tuberculosis infection or disease: an institutional tuberculosis outbreak. Clin Infect Dis. 2002; 35(9):1106-12.

81. Kremers P. In vitro tests for predicting drug-drug interactions: the need for validated procedures. Pharmacol Toxicol. 2002; 91(5):209-17.

82. Marcolino MA, Cantarelli MG, Garcia Junior M. Interações farmacológicas entre medicações clínicas e psiquiátricas. Rev Psiquiatr Clin. (São Paulo). 2004; 31(2):70-81.

83. Rodrigues $A D$, Winchell $G A$, Dobrinska MR. Use of in vitro drug metabolism data to evaluate metabolic drug-drug interactions in man: the need for quantitative databases. J Clin Phamacol. 2001; 41(4):36873.

84. Mula M, Monaco F. Antiepileptic-antipsychotic drug interactions: a critical review of the evidence. Clin Neuropharmacol. 2002; 25(5):280-9. 
85. Ito K, Brown HS, Houston JB. Databases analyses for the prediction of in vivo drug-drug interactions from in vitro data. $\mathrm{Br} \mathrm{J}$ Clin Pharmacol. 2004;58(5):565-8.

86. Bjornsson TD, Callaghan JT, Einolf HJ. The conduct of in vitro and in vivo drug-drug interaction studies: a PhRMA perspective. J Clin Pharmacol. 2003; 43 (5):443-69.

87. Sauer JM, Long AJ, Ring B, Gillespie JS. Atomoxetine hydrochloride: clinical drug-drug interaction prediction and outcome. J Pharmacol Exp Ther. 2004; 308 (2): 410-8 
Anexos 
ANEXO A 
ANEXO B 
Rosimeire Barbosa Fonseca Guastaldi 


\section{ANEXO C}

FICHA DE COLETA DE DADOS DO PRONTUÁRIO

\section{I - Identificação do paciente:}

\begin{tabular}{|c|c|}
\hline Registro & \\
\hline Idade & Sexo( )M ( )F \\
\hline Diagnóstico & \begin{tabular}{l|l} 
Tipo de TMO \\
\end{tabular} \\
\hline Tipo de catete & \\
\hline
\end{tabular}

\section{II- Prescrição de Medicamentos:}

\begin{tabular}{|l|l|l|}
\hline \multicolumn{2}{|l|}{} & \multicolumn{2}{|c|}{ Via } & \multicolumn{1}{|c|}{ Horário } \\
\hline Nome Genérico/Comercial & & \\
\hline 1. & & \\
\hline 2. & & \\
\hline 3. & & \\
\hline 4. & & \\
\hline 5. & & \\
\hline 6. & & \\
\hline 7. & & \\
\hline 8. & & \\
\hline 9. & & \\
\hline 10. & & \\
\hline 11. & & \\
\hline 12. & & \\
\hline 14. & & \\
\hline 15. & & \\
\hline 16. & & \\
\hline 17. & & \\
\hline 18. & & \\
\hline 19. & & \\
\hline 20. & & \\
\hline 21. & & \\
\hline 22. & & \\
\hline 23. & & \\
\hline 24. & & \\
\hline 25. & & \\
\hline 26. & & \\
\hline 27. & & \\
\hline 28. & & \\
\hline 29. & & \\
\hline 30. & & \\
\hline & & \\
\hline & & \\
\hline & & \\
\hline & & \\
\hline & & \\
\hline
\end{tabular}




\section{ANEXO D}

INSTRUMENTO DE COLETA DE DADOS DA LITERATURA

\begin{tabular}{|c|c|c|c|c|c|c|}
\hline COMBINAÇÃO (1) & TIPO DE INTERAÇÃO(2) & $\begin{array}{l}\text { NIVEL DE } \\
\text { SEVERIDADE(3) }\end{array}$ & $\begin{array}{l}\text { NIVEL DE EVIDÊNCIA } \\
\text { CIENTIFICA (4) }\end{array}$ & $\begin{array}{l}\text { IMPLICACCÕES CLINICAS } \\
\text { POTENCIAIS (5) }\end{array}$ & $\begin{array}{c}\text { TEMPO DE INICIO DO } \\
\text { EFEITO (6) }\end{array}$ & $\begin{array}{l}\text { NivEL DE RISCO DE } \\
\text { TERAPIA COMBINADA (7) }\end{array}$ \\
\hline & & & & & & \\
\hline & & & & & & \\
\hline & & & & & & \\
\hline & & & & & & \\
\hline & & & & & & \\
\hline & & & & & & \\
\hline & & & & & & \\
\hline & & & & & & \\
\hline & & & & & & \\
\hline & & & & & & \\
\hline & & & & & & \\
\hline & & & & & & \\
\hline & & & & & & \\
\hline & & & & & & \\
\hline
\end{tabular}

1- Farmacocinética

2- Farmacodinâmica 